\title{
Attentional capture by auto- and allo-cues
}

\author{
ROBERT RAUSCHENBERGER \\ Johns Hopkins University, Baltimore, Maryland
}

\begin{abstract}
In a host of studies, the ability of various types of cues to capture attention has been examined. This article reviews a number of these studies by organizing them into a classification scheme based on the relationship between the putative attention-capturing item (the cue) and the item used to assess the distribution of attention (the probe). The second dimension of this taxonomy divides paradigms of attentional capture into those in which capture is indexed by performance benefits and those in which capture is indexed by performance costs. The relative methodological merits and disadvantages of the paradigms that occupy each of the cells of the resulting two-by-two matrix are discussed. A final section offers a new interpretation of the finding that dynamic cues capture attention.
\end{abstract}

Perhaps one of the most fundamental behaviors of any organism is to orient itself preferentially toward one source of information over another. Even simple onecelled organisms demonstrate this form of behavior, as they move obstinately and unerringly toward lightness and away from darkness. In more complex organisms, such as mammals, the orienting behavior need not involve an overt movement of the body, the head, or even the eyes toward the item of interest but can, instead, be accomplished covertly by orienting the internal perceptual apparatusthe mind's eye (Jonides, 1981) - toward the relevant source of information. This privileging of specific information ${ }^{1}$ over other, simultaneously available information is what we call attention. In some instances, a shift of attention may be initiated by the organism (endogenous control); in others, contingencies of the environment may compel a shift of attention (exogenous control). Such an involuntary shift of attention is referred to as attentional capture.

A long-standing debate about the allocation of attention concerns whether attention is dedicated to objects (e.g., Duncan, 1984) or spatial locations (e.g., Eriksen \& Hoffman, 1973). This debate has largely been eschewed in the literature on attentional capture, and it has implicitly been assumed (which may explain why it is rarely explicitly stated) that the capture of attention involves a shift of spatial attention. Although the same assumption is made throughout this article, it stands to reason that, in most cases, shifts of spatial attention are made to objects. Indeed, in all of the experiments described below, the in-

The writing of this review was supported by NIH Grants R01MH43924 and R01-DA13165 to Steven Yantis. The author thanks Chip Folk, Jan Theeuwes, Steve Yantis, and one anonymous reviewer for their invaluable comments on an earlier draft of the manuscript. Finally, the author expresses his gratitude to Jim Hoffman for his patience and guidance in the revision process. Correspondence concerning this article should be addressed to R. Rauschenberger, Department of Psychology, University of Arizona, Tucson, AZ 85721 (e-mail: rauschen@u.arizona.edu).

Note-This article was accepted by the previous editorial team, while John T. Wixted was editor. voluntary shift of attention was elicited by an object (the cue $^{2}$ ). What constitutes an object, however, is no straightforward question and remains unresolved despite valiant attempts to make the object concept more tangible (e.g., Scholl, Pylyshyn, \& Feldman, 2001). More consequential, in any case, for the study of attentional capture is the fact that, regardless of whether attention attaches itself to locations or to objects, the question of what draws attention involuntarily in the first place remains highly contentious even after decades of research.

\section{The Problem of Multiple Paradigms}

Much of the debate about which types of cues do or do not involuntarily capture attention has been conducted across different types of paradigms, which may have contributed to the proliferation of mutually contradictory contentions in the literature. Furthermore, each paradigm of capture is accompanied by its own operationalization of capture-a circumstance that has not contributed to resolving the tension between seemingly contradictory findings. In some paradigms, for example, capture surfaces as an impairment in performance (e.g., Folk, Remington, \& Johnston, 1992; Theeuwes, 1991a), whereas in others, it does so as a performance benefit (e.g., Yantis \& Jonides, 1984). Each way of operationalizing capture has its own inherent difficulties.

What is needed, therefore, is a review that organizes the literature with particular attention to the advantages and disadvantages of the different paradigms used to investigate attentional capture. Such a discussion strictly separated into different paradigms allows the evidence from one study to be discussed in the context of evidence from other studies that is of a like nature. The strength of the evidence provided by a given paradigm is only ever relative to the type of conclusions that this class of paradigms affords.

\section{A Method-Based Review}

Accordingly, the purpose of the following review is to organize attentional capture paradigms on the basis of 
the different methods employed to reveal capture. (See Simons, 2000, for a different, but likewise methodologybased, breakdown of the literature.) As was stated above, organizing the literature by a methodological rather than a theoretical framework is desirable for a variety of reasons. The former approach provides researchers, who often have widely diverging theoretical positions, with a common currency for discussing the literature on capture: Although the utility of any given methodologybased taxonomy may be debatable, that particular taxonomy will ultimately be less controversial than one derived from a strong theoretical position.

Furthermore, although a taxonomy based on the different paradigms employed in the study of capture can be devised without reference to theory, the paradigms themselves are not free of theoretical burden. A methodological framework is, therefore, not mute on the theoretical issues surrounding capture, as would appear to be the case at first glance. Indeed, exposing the theoretical implication of each type of paradigm is one of the goals of this review. Ultimately, therefore, a methodological framework will be of organizational, theoretical, and practical use because it will elucidate the benefits and disadvantages of each particular class of paradigms.

\section{A New Taxonomy of Capture Paradigms}

The particular taxonomy I would like to propose is based on the relationship between the attention-capturing stimulus and the stimulus used to assess the spatial distribution of attention. I will refer to the former as the cue and to the latter as the probe. There are several advantages to basing a classification of attentional capture paradigms on the relationship between the probe and the cue. First, given this very general definition of cue and probe, it is always possible to identify both in any given attentional capture experiment. In any such experiment, one item (or event) is examined for its potential to capture attention (whether it does so or not). This is the cue. Assessing whether this item truly captures attention requires an item that will reveal the spatial distribution of attention in the display. This is the probe. (In some paradigms, the same item may function as both cue and probe, as will be discussed below.) Identifying both the cue and the probe may be accomplished without having to commit to a specific theoretical position, which, once again, facilitates communication about different approaches to the study of attentional capture.

A second advantage to using the relationship between the cue and the probe to classify attentional capture paradigms is that, although this affords a theoretically noncommittal classification, it uncovers some of the theoretical questions that are latently present in certain designs. These questions will be treated in the following section. Finally, adopting a definition of cue that comprises different classes of cues provides a unified concept of cue, which, in turn, permits a more parsimonious discourse about attentional capture paradigms. Traditionally, experiments have been referred to as cuing experiments when a spatial location in the display was marked by means of an item singling out that location. This item could either be flashed briefly (e.g., Posner \& Cohen, 1984) or remain on the display until a response was issued (e.g., Theeuwes, 1991b). What characterized the cue in each case was the fact that it was extrinsic to the items to which a response was made. There is no reason, however, not to consider a singleton in search a cue as

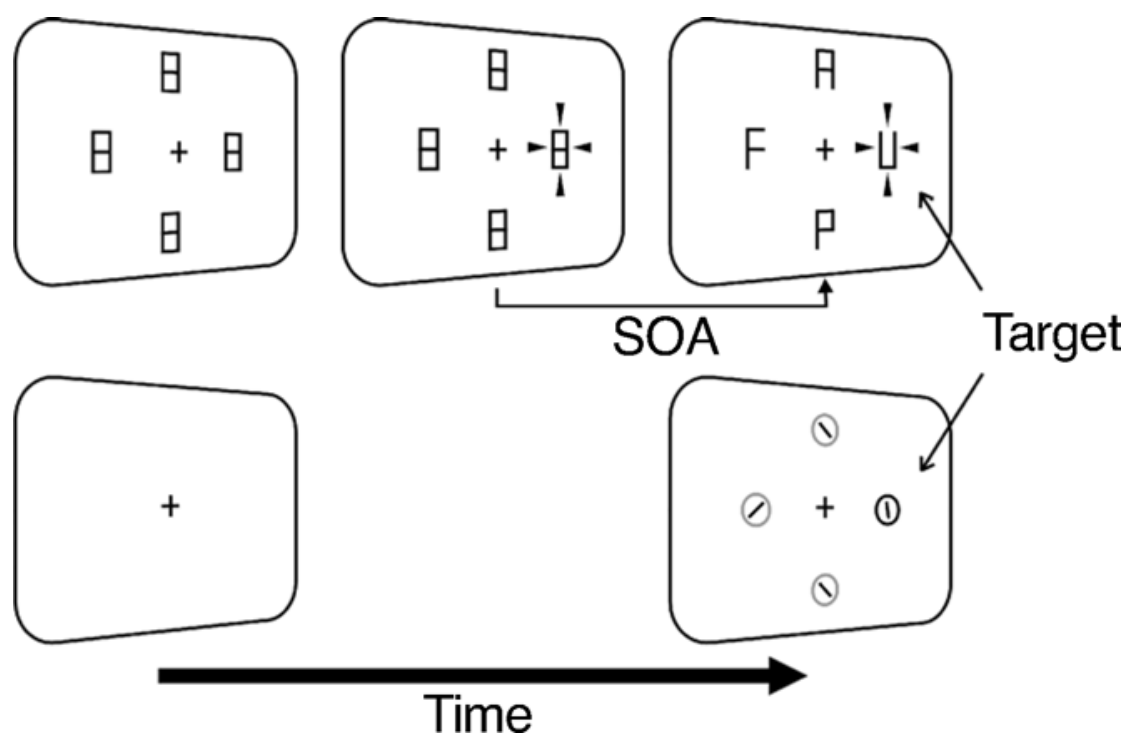

Figure 1. Two instances of an allo-cue paradigm. The top panel shows an example of a conventional precuing paradigm. The bottom panel illustrates an example of a visual search task that uses the allo-cue paradigm. In both examples, the cue indicates the position of the target. 
well. Like the more traditional cue, the singleton marks a specific spatial location in the display (see Figure 1). The only difference between the traditional cue and the singleton is that the singleton itself may be part of the set of items to which a response will potentially be made. Therefore, it may play a dual role as cue and as probe (see below).

These two classes of cues (the traditional and the singleton cues) map onto one dimension of the two-by-two matrix that I will use to structure my following review of the attentional capture literature (see Figure 2). Along this dimension of the matrix, capture paradigms are separated into those in which the putative attention-capturing item serves both as cue and as probe (auto-cue) and those in which the effects of the cue are assessed by the presentation of a separate probe (allo-cue). The second dimension classifies capture paradigms based on whether capture is manifested by a benefit or an impairment in performance.

\section{Allo- and Auto-Cues}

In the more traditional cuing paradigm, the extent to which attention is captured is measured by presenting a spatial cue that could potentially draw attention to itself. Whether attention was indeed drawn to the spatial location of the cue is then assessed using a probe that reveals the present locus of the attentional focus (e.g., Folk et al., 1992; Jonides, 1981; Lambert \& Hockey, 1991; Müller \& Rabbitt, 1989; Posner \& Cohen, 1984; Posner, Cohen, $\&$ Rafal, 1982). A response is only ever made to the probe. The logic of such cuing paradigms is that the response to the probe item will be affected by the extent to which the cue is capable of drawing attention either away from or to the probed location. If attention is directed to the location of the cue and the cue does not coincide spatially with the (following) probe, responses will be slower than if the cue and the probe do coincide spatially. As an alternative to measuring the response time (RT) to the probe, it is also possible to present the probe very briefly and measure participants' accuracy in detecting or discriminating the probe (e.g., Nakayama \& Mackeben, 1989). In order to determine whether the difference in performance between spatially coincident and spatially discrepant cue-probe pairs reflects an impairment in performance (with discrepant pairs) or an improvement in performance (with coincident pairs), a neutral cue condition is often included as a baseline (e.g., Folk et al., 1992; Folk, Remington, \& Wright, 1994; Jonides, 1981; Müller \& Rabbitt, 1989; Warner, Juola, \& Koshino, 1990). However, determining the appropriate neutral cue is often not entirely straightforward (Jonides \& Mack, 1984).

The attention-capturing cue in the class of paradigms described above is altruistic in the sense that it captures attention for an item other than itself: the probe. Because of the cue's attention-mediating property, I will refer to paradigms in which there are separate cues and probes as allo-cuing (or other-cuing) paradigms. These paradigms can be contrasted with those in which the item used to probe the location of the attentional focus cues itself. I will refer to the latter as auto-cuing (or self-cuing). Most visual search experiments involving singletons ${ }^{3}$ fall into this category. However, not all such visual search experiments can be classified as auto-cue experiments: In the additional singleton paradigm (Simons, 2000), for example, the cue and the probe do not coincide in the same item. In a study by Theeuwes (1991a), for instance, the participants' task was formally a search task. The target

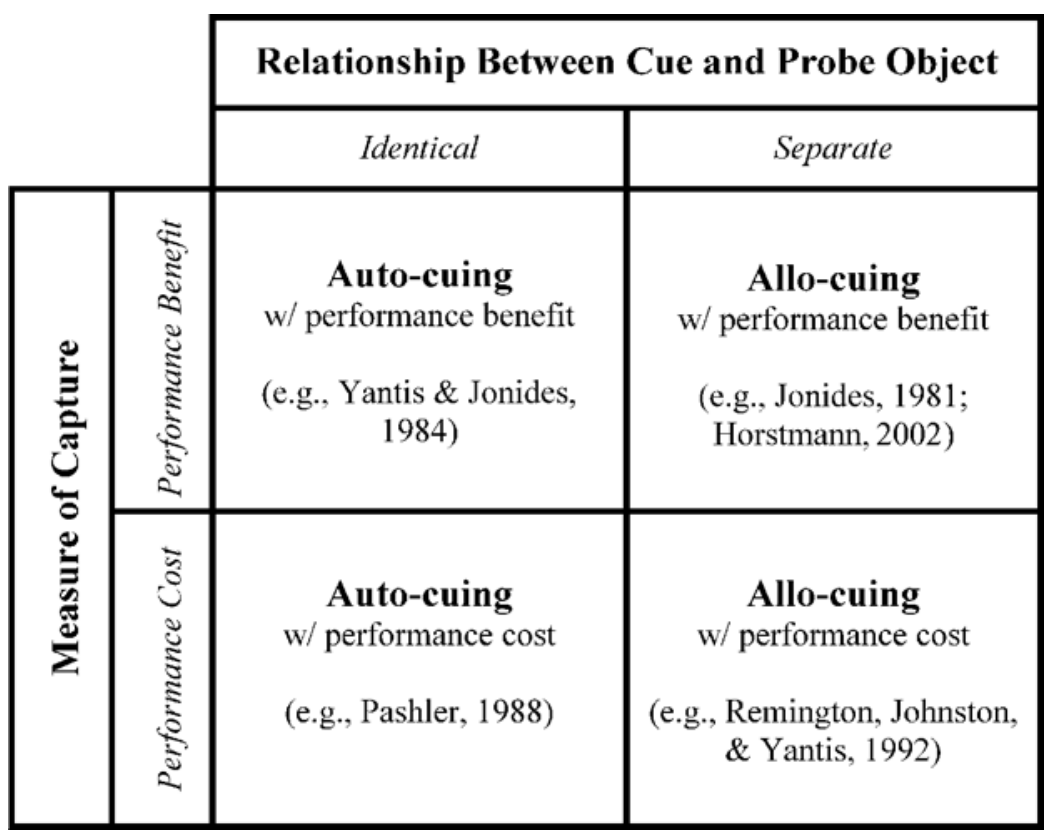

Figure 2. A taxonomy of attentional capture paradigms. See the text for details. 
(i.e., the probe) was a line segment that differed in orientation from the other line segments in the display. The putative attention-capturing item (i.e., the cue), however, was one of the circles inside of which the line segments were presented (see Figure 1, bottom panel). The task in this case might, therefore, have been visual search, but the underlying paradigm was an allo-cue paradigm.

Temporal parameters of allo- and auto-cues. At first glance, the distinction between allo- and auto-cues may appear to hinge on the stimulus onset asynchrony (SOA) between the cue and the probe, in which case autocuing collapses into allo-cuing with an SOA of zero (see Figure 1). A comparison between the effects of allo-cues at extremely short SOAs and those of auto-cues (which, by their very nature, entail a zero SOA; however, see below) is highly informative in this regard. A number of studies have shown the effects of allo-cues to be absent or highly diminished at SOAs shorter than $100 \mathrm{msec}$ or so (e.g., Chastain \& Cheal, 1998, 1999a; Cheal \& Chastain, 1998; Müller \& Rabbitt, 1989; Nakayama \& Mackeben, 1989; Warner et al., 1990). By contrast, auto-cues produce attentional effects even though they are presented simultaneously with the display onset-that is, at a zero SOA (cf. Folk et al., 1992, Experiment 4; Theeuwes, 1995b; Theeuwes, Atchley, \& Kramer, 2000; Yantis \& Jonides, 1984). This difference could possibly be explained by the fact that the attention drawn by the cue in the allo-cue paradigm is in part object based (cf. Duncan, 1984) and needs to be transferred from the cue object to the probe object. In the auto-cue paradigm, by contrast, the attentiondrawing object (i.e., the cue) is at the same time the probe used to assess the distribution of attention, making a transfer unnecessary. ${ }^{4}$ These remarks are speculative, but they potentially offer a useful way of thinking about the allocation of attention in allo- and auto-cue paradigms.

Irrespective of the mechanisms underlying the difference between allo- and auto-cues, the effects observed in either type of paradigm can perhaps be summarized in the following way (see Figure 3). Experiments in which autocues are used either produce evidence of capture or not, depending on the stimulus, as will be discussed in detail below (Figure 3, right panel). A more complicated picture emerges for allo-cues: The more traditional cuing experiments tend to show neither performance benefits nor costs at short SOAs, whereas benefits and/or costs emerge at longer SOAs (e.g., Müller \& Rabbitt, 1989; Nakayama \& Mackeben, 1989). When allo-cues are paired with a visual search task, costs are generally observed at short SOAs (e.g., Theeuwes, 1991a, 1992, 1994), but no benefits (e.g., Horstmann, 2002; Theeuwes, 1990). One exception (although possibly not the only one) is abruptly onsetting new objects (see below). At longer SOAs, by contrast, it is possible to observe performance benefits with allo-cues as well (e.g., Horstmann, 2002).

Two sets of studies are instructive in this regard. First, experiments by Chastain and Cheal (1998, 1999a; Cheal \& Chastain, 1998) suggest that allo-cues generally have slow rise times, but less so when they happen to be onset

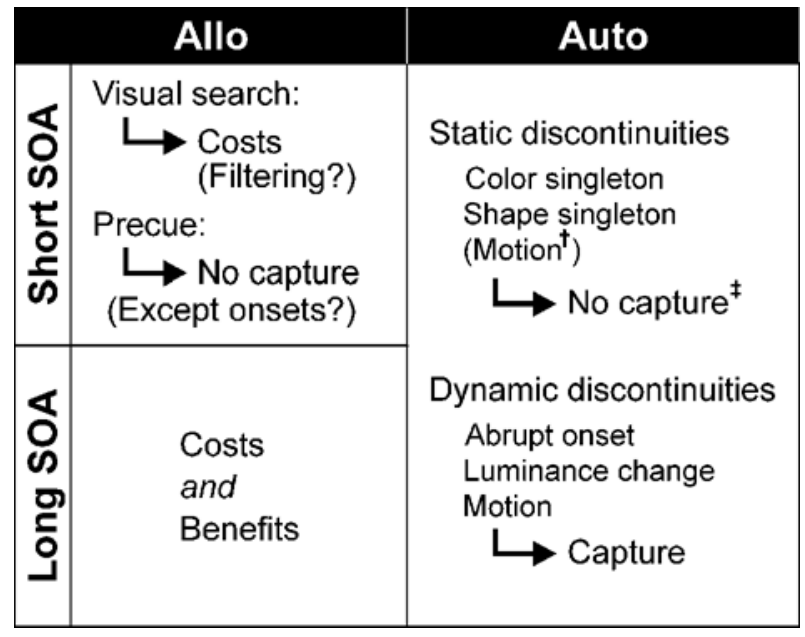

Figure 3. Schematic summary of results obtained with various assays of attentional capture. See the text for details. † Motion should properly be classified as a dynamic cue, but, as has been argued in the main text, there are certain types of motion cues that can be considered "static" in some sense. $¥$ The conclusion that static discontinuities do not capture attention is based on the premise formulated by Yantis (1993b) that the target-defining property should not be part of the observer's attentional set. It is derived primarily from evidence obtained using the $1 / d$ paradigm (see the text). The reader should consult Folk, Remington, and Johnston $(1992,1993)$ for a dissenting perspective.

singletons. In these experiments, the cue was highly task relevant and, therefore, cannot be said to have captured attention involuntarily (cf. Yantis, 1993b), as Chastain and Cheal (1998) pointed out. Even under these conditions, however, the full effect of the cue did not emerge until the 100-msec range indicated by other studies. Chastain and Cheal (1998, 1999a; Cheal \& Chastain, 1998) contrasted single-element cues (i.e., essentially onset items) with multielement cues (i.e., essentially singleton search displays; see Figure 4). Of the two, the latter had slower rise times than the former, suggesting that not all allo-cues have similar temporal properties.

Second, Horstmann (2002) presented an unexpected color singleton allo-cue either simultaneously with a letter target (systematically replicating Gibson \& Jiang, 1998) or $500 \mathrm{msec}$ prior to the appearance of the target letter. Only in the latter case did he observe any performance benefit (in terms of accuracy). Indeed, his rationale for using the longer SOA was the possibility that the shift of attention elicited by the cue required more time than the $86 \mathrm{msec}$ allowed by Gibson and Jiang in their study, which failed to show capture. Using a color singleton auto-cue in his third experiment, Horstmann (2002) again found evidence of efficient attentional guidance toward the uniquely colored item. The set size slopes he observed (12.7 msec/item) were too large to permit the conclusion that attention was captured in any strict sense (see below), but a clear difference emerged nonetheless between the allo- and the auto-cues used in Horstmann's study. 


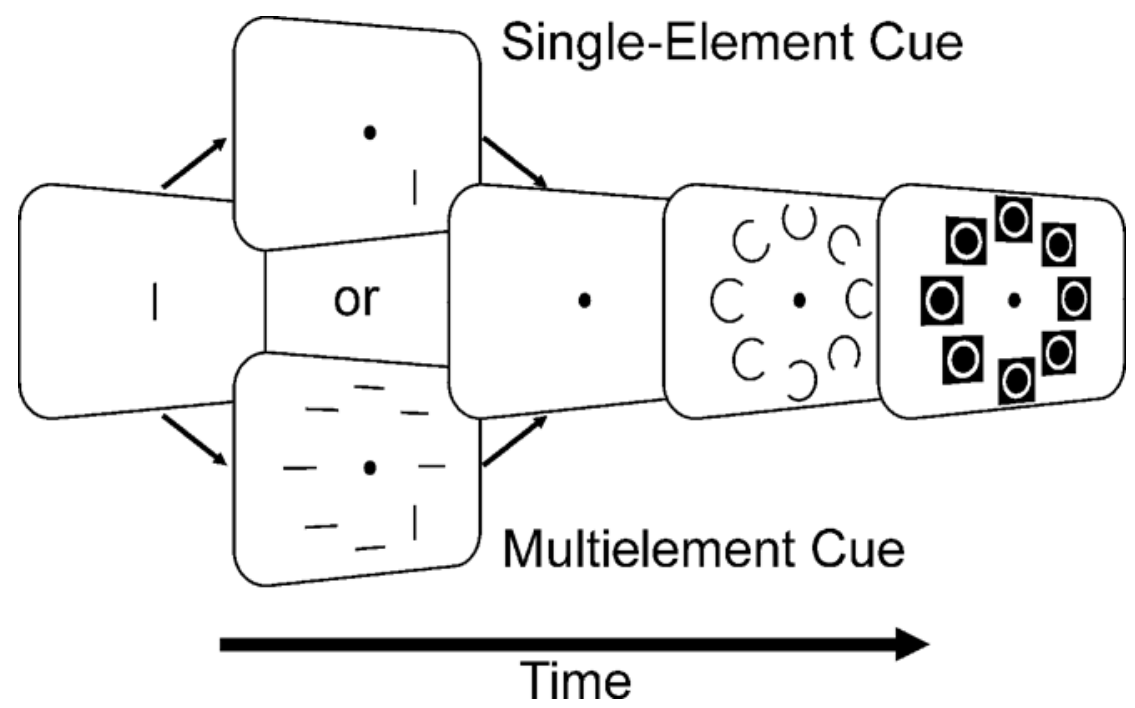

Figure 4. Example of displays used by Chastain and Cheal (1999a). The single-element cue constitutes an abrupt onset cue, and the multielement cue constitutes a feature singleton cue.

\section{Performance Benefits and Performance Costs}

The temporal parameters of allo-cues point to some methodological concerns pertaining to the operationalization of capture as a performance benefit. Relying on performance benefit raises problems for two mutually opposing reasons. On the one hand, the time course of allo-cues suggests that the effect of the cue may have a delayed onset for anything but abrupt onsets. It is, therefore, possible that cues appearing at very short SOAs (e.g., in visual search) may not have sufficient time to exert their full effect (cf. Horstmann, 2002; however, see also Theeuwes et al., 2000). On the other hand, owing to the shorter rise time associated with abrupt onset cues, any attentional effects elicited by the cue may have already dissipated by the time a probe is presented ${ }^{5}$ if the SOA is long (e.g., precue paradigm). Unfortunately, relying on performance costs can equally well raise problems because, in some cases, it is not clear whether these costs are due to a spatial allocation of attention to the distractor or to nonspatial attentional factors (see below; Folk \& Remington, 1998; Treisman, Kahneman, \& Burkell, 1983).

Auto-cue paradigms are subject to the same problem if capture is inferred from a performance decrement when the singleton item is not the target (additional singleton paradigm in Simons's, 2000, terminology): The deleterious effect of the distractor may arise from purely nonspatial factors. Resorting to a reliance on performance benefit as a measure of capture does not provide a satisfactory solution to this problem, however. Although such a performance benefit may reflect a spontaneous allocation of attention to the cued item, in visual search, it may equally well simply represent a prioritization of the target item in the search queue (Yantis \& Johnson, 1990; Yantis \& Jones, 1991). In other words, it is conceivable that an item receives a high priority tag in search and that search begins with this item-producing the set size independence that is normally taken as the hallmark of capture-but that the item otherwise fails to elicit an automatic redirection of spatial attention.

\section{A SURVEY OF THE LITERATURE}

\section{Organization of the Review}

The following review, then, is organized around these two basic dimensions: the type of paradigm employed (allo- or auto-cue) and the operationalization of attentional capture (benefit or cost). As the preceding discussion of the different time courses of abrupt onset versus other types of cues illustrates, the review furthermore needs to be conducted with respect to the type of cue investigated for its potential to capture attention. Broadly, cues can be classified as either static or dynamic (cf. Folk et al., 1992). The former include such cues as color or shape singletons and will be discussed first. The latter include such cues as motion singletons or abrupt onsets and will be discussed second. Within each type of cue, the evidence for attentional capture is examined separately for allo- and auto-cues and, furthermore, with respect to whether capture is operationalized as a performance cost or a performance benefit. As was mentioned earlier, special attention will be given to the methodological merits and drawbacks of each cell of the matrix proposed in Figure 2, and the evidence for the ability of a particular cue to capture attention will be critically assessed with reference to these methodological considerations.

\section{Being Different: Attentional Capture by Static Singletons}

In this section, the possibility that featural singletons capture attention in an involuntary fashion will be con- 
sidered. As has been pointed out by S. Todd and Kramer (1994) and Yantis and Egeth (1999), a number of theories of visual search predict that items that are unique with respect to their context should draw attention to themselves (e.g., Cave \& Wolfe, 1990; Duncan \& Humphreys, 1989; Koch \& Ullman, 1985; Ullman, 1984; Wolfe, Cave, \& Franzel, 1989). Of some importance to the following discussion is the question of whether an awareness of the presence of a featural singleton requires a shift of spatial attention to the cued location in the first place. This question is of obvious relevance because, for the purposes of this review, attentional capture has been defined as an involuntary shift of spatial attention to the location of the attention-capturing object or event. Precisely here, however, methodological issues arise, as shall be seen.

\section{Performance Benefits With Auto-Cues}

The pop-out paradigm. Do items that pop out capture attention? The observation that featural singletons frequently pop out of a display and are consequently detected very efficiently has often been taken as evidence that featural singletons capture attention (cf. Yantis \& Egeth, 1999). In instances of pop-out, however, the defining and the reported attributes ${ }^{6}$ of the target are identical: What is required of participants is the mere detection of the presence of a target. The conclusion that the featural singleton captured attention depends strongly on the premise that one brings to the interpretation of the pop-out phenomenon. For example, models in which spatial attention is deployed to the items in a search display in order of their relative salience (e.g., Cave \& Wolfe, 1990; Duncan \& Humphreys, 1989; Koch \& Ullman, 1985; Ullman, 1984; Wolfe et al., 1989) would suggest the conclusion that because the pop-out item was detected efficiently, it was always visited first by the attentional search mechanisms. Such a conclusion is equivalent to the inference that the pop-out item was prioritized in search and, hence, by some definitions, captured attention.

An alternative approach would be to assume that featural singletons are detected without the spatial deployment of attention. Feature integration theory (FIT; Treisman \& Gelade, 1980; Treisman \& Sato, 1990), for example, proposes that a featural singleton is detected by monitoring feature maps for unique activity, and irrespective of the spatial location of the activation (see, however, Treisman, 1988, for the suggestion that attention is subsequently summoned to the pop-out item). Treisman and Gelade have reported findings consistent with this idea. In a pair of final experiments, they presented participants with masked pop-out displays. Treisman and Gelade (1980, Experiments 8 and 9) observed that the participants were relatively poor at correctly locating a feature target even when they had correctly identified it, suggesting that although the participants were able to detect a singleton successfully, they did so without (necessarily) moving their attention to the location of the target.
The difficulty with allowing the defining and the reported attributes of the target to coincide is that one lacks evidence that attention was, in fact, spatially deployed to the target. All one has is evidence that the presence of the singleton was registered by the observer, as proposed by FIT. There are two solutions to this problem. First, one can assess the spatial distribution of attention, using a separate probe. However, using a separate probe renders the experiment into an allo-cue paradigm, which may be subject to a different attentional dynamic (see above). Second, one can use the reported attribute of the target to probe whether the participants actually attended the feature singleton target. However, this solution brings with it the new problem that the identification of the target may require a focusing of attention on the to-be-identified target. In this case, it is possible that the singleton is first detected without its having drawn attention to itself and attention is then narrowed to the singleton to accomplish target identification (cf. Bravo \& Nakayama, 1992; Di Lollo, Kawahara, Zuvic, \& Visser, 2001; Nakayama \& Joseph, 1998; Treisman, 1988). Any spatial allocation of attention to the feature singleton would be the consequence of the second stage, rather than the result of capture by the singleton.

This problem was in some ways circumvented by Mounts and Melara (1999), who made the reported attribute of the target a simple feature, itself capable of producing pop-out in search if it defined the target. In other words, both the defining and the reported attributes of the target were easily discriminable features. For example, the participants' task would be to find a righttilted line among left-tilted lines and to report the color of the target line. This condition was compared with a condition in which the participants had to report the orientation of the tilted target line-that is, to make a discrimination along the same dimension as that which defined the target. Although both conditions involved discriminations along single featural dimensions, performance was better in those conditions in which the defining and the reported attributes both varied along the same dimension. Mounts and Melara concluded that search proceeds in feature, not object, space. Registering the presence of a discontinuity in a particular dimension does not automatically entail access to the other features of the object that possess the unique target-defining feature. These results parallel and extend those of Treisman and Gelade (1980), discussed earlier. They confirm that even when the reported attribute is a simple feature, the information that is available about the pop-out item is restricted to the target-defining feature. Hence, both direct (Treisman \& Gelade, 1980) and indirect (Mounts \& Melara, 1999) assessments of the spatial distribution of attention in a pop-out task have failed to provide evidence that a feature singleton attracts attention to itself.

Does pop-out require attention at all? The claim that feature singleton detection does not require a spatial deployment of attention is not synonymous with the claim 
that singleton detection does not require attention at all. If it could be determined conclusively that feature singleton detection does not require attention, the question of whether singletons elicit an automatic shift of attention would become moot. Thus far, however, the issue has remained unresolved. On the one hand, Braun and colleagues (Braun \& Sagi, 1990, 1991) have reported results that suggest that observers can withdraw attention from a singleton detection task at no cost to the latter. On the other hand, a study by Joseph, Chun, and Nakayama (1997) showed performance costs implicating attention in the detection of feature singletons (see also Theeuwes, Kramer, \& Atchley, 1999; but see also Braun, 1998; Nakayama \& Mackeben, 1989, Experiment 1). The difficulty with denying an attentional involvement in feature singleton detection is that any effort to support this position empirically is tantamount to confirming the null hypothesis: It can always be objected that the manipulation intended to deplete attentional "resources" has failed to "consume" all attention (cf. Joseph et al., 1997; Nakayama \& Joseph, 1998).

A reasonable proposal put forth by Nakayama and Joseph (1998; Bravo \& Nakayama, 1992; Nakayama, $1990,1999)$ is that pop-out or singleton detection represent instances of texture segregation, ${ }^{7}$ in which the target emerges as a figure against its background of nontargets. In this schema, attention is distributed across the entire display for feature singleton detection, in order to allow a coarse segmentation of the display into target and nontargets. Although attention is, therefore, a necessary component of feature singleton detection, a spatial shift, or a narrowing of attention, is not necessarily entailed by this scheme. This proposal is largely consistent with extant models of search, such as attentional engagement theory (AET; Duncan \& Humphreys, 1989, 1992) or FIT (Treisman, 1982, 1992; Treisman \& Sato, 1990). It is bolstered by the finding that increasing the density of the nontarget elements in singleton detection improves the efficiency of search, whereas it leaves discrimination relatively unaffected (Bravo \& Nakayama, 1992; see also Bacon \& Egeth, 1991, and Folk \& Annett, 1994, Experiment 3, who likewise found that target detection became more efficient with an increasing number of nontargets).

Assessment. Although pop-out targets can be detected very efficiently, there is little or no compelling evidence for their ability to capture attention in the face of the methodological limitations of the pop-out paradigm. Rather, the subjective impression that pop-out items capture attention may arise from the fact that they very readily segment from the textural context formed by the distractor elements. Because pop-out targets are so highly salient, they produce an acute awareness of their presence (cf. Folk \& Egeth, 1989; S. Todd \& Kramer, 1994). In all of the studies discussed so far, the pop-out item was always the target. In some sense, therefore, the response required in these experiments confounded an awareness of the presence of the singleton item and target detection.
The 1/d paradigm. A more appropriate test of the question of whether singletons capture attention would be provided by a paradigm in which these two factors are unconfounded. One effective approach to this problem is to make the singleton the target on only $1 / d$ of all trials, where $d$ is the number of items in a search display. In such a design, the probability that the singleton will be the target on any given trial is the same as that for the nonsingleton items in the display. This arrangement allows room for the possibility that observers are indeed keenly aware of the presence of the singleton on each trial but the singleton does not capture attention. However, even the $1 / d$ design does not safeguard completely against the use of particular strategies by participants that may give the appearance of capture. Notably, participants may be inclined to rely on a salient singleton item as a landmark from which to begin search (cf. S. Todd \& Kramer, 1994). In this case, appropriate data analysis techniques, as will be discussed below, may help distinguish between true capture and attentional guidance.

In a number of studies, the potential of feature singletons to attract attention has been examined using a 1/d probability. Jonides and Yantis (1988) had participants search for luminance (bright among dim letters) and color (red among green and vice versa) singletons. In both searches, the participants were aware of the presence of the feature singleton (see Jonides \& Yantis, 1988, p. 348), but responses to singleton targets were not any faster than responses to nonsingleton targets. ${ }^{8}$ This result is consistent with the idea that feature singletons are highly salient and impress their presence upon the consciousness of the observer but fail to capture attention. A study by S. Todd and Kramer (1994) lends further support to this idea. S. Todd and Kramer confirmed that color and luminance singletons do not capture attention. At the same time, they also showed that with an increasing number of display items, uniquely colored or luminous items were increasingly likely to be inspected before other items. To distinguish the latter effect from true capture, S. Todd and Kramer referred to it as attentionalmisguidance. S. Todd and Kramer concluded that the participants used the progressively more salient singleton as a landmark to guide search.

The strongest evidence so far that color singletons do not capture attention comes from a study by Gibson and Jiang (1998). Although the singleton was always the target in this study, the participants were not specifically searching for a singleton, because the singleton appeared on only a single trial and the participants were not expecting it. This method is very interesting because the target is $100 \%$ correlated with the singleton and yet, as in the studies in which $1 / d$ probability was used, the participants have no incentive to look deliberately for a singleton. Under these conditions, Gibson and Jiang found no evidence of capture. Gibson and Jiang's study has recently been criticized by Horstmann (2002) for not allowing a sufficient cue-probe SOA to permit capture ef- 
fects to unfold. As was described earlier, using a long SOA, Horstmann obtained evidence of prioritization in a variant of Gibson and Jiang's paradigm. However, because Horstmann's slope estimates were quite steep for capture (roughly $13 \mathrm{msec} /$ item), it is not clear whether his results represented true capture or, rather, a form of attentional guidance.

Yantis and Egeth (1999; see also Proulx, 2002) observed efficient search with both a luminance singleton (bright item among dim ones) and a size singleton (large item among small ones). Why the results of these experiments were at odds with previous, largely negative findings is still an open question. One possibility, which has not yet been explored, is that, for items that vary along a prothetic dimension, ${ }^{9}$ displays are searched in a hierarchical fashion. The visual system may be disposed, for example, to search through all large items first, then the next smaller items, and so forth. If the largest item is the target, search ends there, giving the appearance of attentional capture. Searching a display in the proposed hierarchical fashion represents a sensible strategy because items at the large extreme of a dimension are typically more easily discerned (cf. Yantis \& Egeth, 1999; see also S. Todd \& Kramer, 1994, who observed attentional misguidance with bright, but not with dim, singletons). A similar systematic bias in the order of search has been reported for eccentricity, with observers starting at the center of a display and working their way out toward the periphery (Wolfe, O’Neill, \& Bennett, 1998; see Carlson $\&$ Shomstein, 2001, for the even more interesting suggestion that search proceeds from the center of attention outward).

Assessment. One of the central methodological issues in the study of involuntary attentional capture is the removal of incentives to attend to the putative attentioncapturing cue. A method that has proven quite useful in this regard is the $1 / d$ paradigm. Using this paradigm to investigate the ability of feature cues to attract spatial attention in a bottom-up fashion has produced largely negative results. The few exceptions (Proulx, 2002; S. Todd \& Kramer, 1994; Yantis \& Egeth, 1999) may represent forms of attentional (mis-)guidance. The ambiguity of the shallow search slopes (guidance vs. capture) shown in these studies may be resolved by providing convergent evidence from other paradigms-for example, by using a design in which the cue is never the target.

Summary. In summary, despite the popularity the pop-out paradigm has enjoyed, this paradigm provides only flawed evidence of capture. For one, the reported and the defining attributes of the target are identical, offering an incentive for participants to search deliberately for the putative attention-capturing item. Furthermore, the case can be made that pop-out targets do not even demand search proper, which, almost by definition, entails a shift of spatial attention. Instead, it may be that the presence of a pop-out target can be registered without (spatial) attention to the pop-out item.

There are few, if any, solutions to the methodological deficits of the pop-out paradigm. The question of whether an awareness of the presence of the target features coincides with an imperative spatial shift of attention to the target can potentially be addressed by assaying the target location with a separate probe (e.g., Bichot, Cave, \& Pashler, 1999; Cave \& Zimmerman, 1997; Cepeda, Cave, Bichot, \& Kim, 1998; Kim \& Cave, 1995; Mounts, 2000). This solution, however, converts the auto-cue pop-out paradigm into an allo-cue paradigm, thereby fundamentally altering the nature of the paradigm. Because, in many cases, the first display in these studies (i.e., the pop-out display) requires participants to respond overtly and explicitly to a display item, the subsequent probe does not measure the involuntary capture of attention, but merely its distribution in the display. Furthermore, converting the pop-out into an allo-cue paradigm only diverts the problem, because the latter possess its own inherent difficulties.

An additional methodological issue that has received little attention so far is the overly large reliance on search slopes to infer the potential of pop-out targets to capture attention. The intercept of the search function has largely been ignored for pop-out targets, although it may afford a significant source of information about the nature of the search. In a study by Wang, Kristjansson, and Nakayama (2001), for example, a conjunction odd-one-out target was capable of producing pop-out, as defined by the shallowness of the search slope. The intercept for the search function, however, was quite large (on the order of $800-1,000 \mathrm{msec}$ ), suggesting that a significant amount of preprocessing had to transpire before the presence of the target could be reported. Without consideration of the intercept, one might have concluded that conjunction targets can pop out even in a heterogeneous display, due to efficient preattentive guidance. However, it makes little sense to consider an effect as preattentive that requires a full second or so to develop. Instead, Wang et al. sensibly attributed the effect to midlevel (i.e., neither top-down nor bottom-up) processes.

On the basis of all of the preceding methodological considerations, therefore, pop-out paradigms should perhaps be abandoned as a source of evidence about the ability of various types of (feature) cues to capture attention in a truly (or, at least, largely) stimulus-driven fashion. A more methodologically robust approach is offered by the $1 / d$ paradigm, as has been discussed above. The difficulties entailed by this paradigm are relatively minor. The central issues that arise with the $1 / d$ paradigm are the question of how to distinguish attentional guidance (which results in efficient but nonzero search slopes) from the occasional failure of the imperative item to capture attention (which would likewise yield greater than zero mean slopes) and the burden of demonstrating that an item is not merely prioritized in the search queue but commands attention away from other search items. The latter question may, perhaps, best be addressed by converging evidence from studies in which attentional capture is operationalized as a performance cost: If an item is capable, for example, of demanding attention even when it is never the target, thereby incit- 
ing a performance cost, it stands to reason that, conversely, it accrues benefits because it tyrannically draws attention to itself (and is not merely placed first in the search queue).

The question of how to rule out mere attentional guidance can be approached, on the one hand, by demonstrating that manipulations that facilitate texture segregation (such as an increase in the density of the search display) lead to more efficient search, as they did in S. Todd and Kramer's (1994) experiments. Items that truly capture attention should not need to depend on increased salience to afford efficient selection. Indeed, many of Yantis's participants were unaware of the abrupt onset manipulation when queried following the experiment (see Yantis, 1993b, footnote 2), and yet the abrupt onset items effectively captured the participants' attention.

On the other hand, in the absence of 0 -msec/item search slopes, appropriate data analysis techniques may be used to assess whether an item receives absolute priority in search or merely yields relatively efficient search (e.g., Enns, Austen, Di Lollo, Rauschenberger, \& Yantis, 2001; Theeuwes, 1990). Enns et al., for example, plotted the search slopes derived from the shortest 5\%, 10\%, $15 \%$, and so forth of the RTs over each 5\% RT bin and showed that an abrupt onset singleton produced shallow search slopes for all but the longest RTs (trials on which participants may have had a lapse of concentration, etc.; see Figure 5). Reporting only the mean search slope would have underestimated the efficiency of search in this case. Polarity change singletons (items that changed their direction of contrast with respect to the background; see below), by contrast, produced only shallow slopes for the very shortest RTs - trials on which these singletons were probably inspected first by mere chance or due to guidance. These two qualitatively different results could be used more widely in deciding how to interpret nonzero but fairly shallow search slopes.

\section{Performance Costs With Auto-Cues}

As was suggested above, because prioritization accounts can always be invoked to explain highly efficient search, it is desirable to have corroborating evidence from experiments in which capture reveals itself through an interference with search. The logic is that if something truly captures attention, it will not merely be placed at the top of the search queue when it happens to be the target, but will also demand attention when it is not the target. Fortuitously, there has been some overlap in the types of singletons that have been examined in experiments in which capture is operationalized as an impairment in performance and those in which it has been operationalized as a performance benefit. For example, Pashler (1988, Experiment 6), Theeuwes (1991a, 1992, 1994), Ghirardelli and Egeth (1998), Folk, Leber, and Egeth (2002), and Theeuwes and Burger (1998) all examined the ability of task-irrelevant color singletons to interfere with target detection. Of these studies, Theeuwes

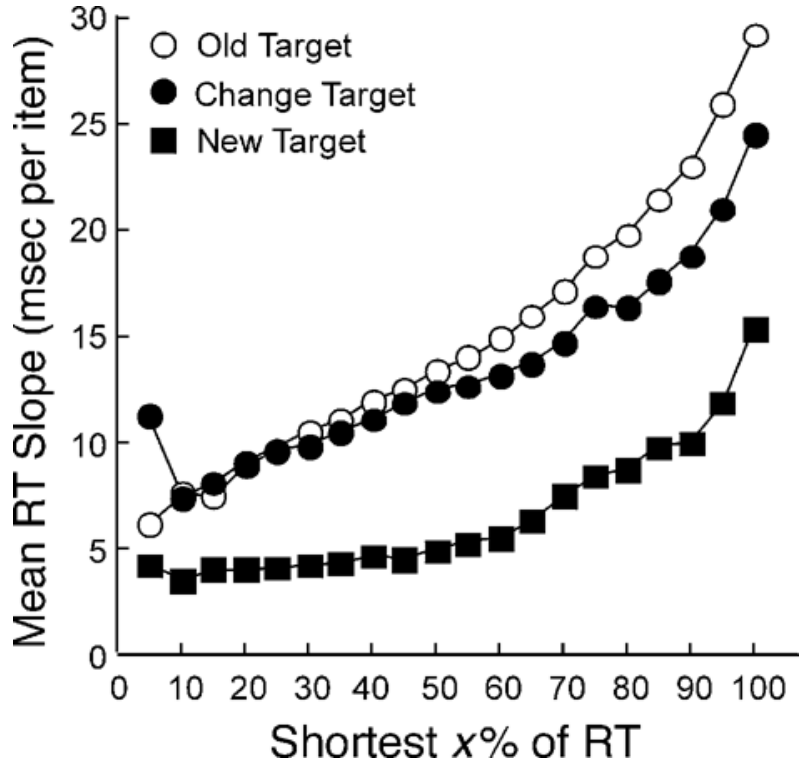

Figure 5. The response time (RT) analysis used by Enns, Austen, Di Lollo, Rauschenberger, and Yantis (2001) shows that slopes for abrupt onsets are relatively flat (below $10 \mathrm{msec} / \mathrm{item})$ all the way out to the 80 th or 85 th percentile, whereas those for luminance change items quickly become relatively steep (starting with the 30th percentile). The efficient search observed in the latter case at low percentiles presumably reflects trials on which search commenced at the singleton item by chance. The inefficient search in the abrupt onset case most likely reflects trials on which either the onsetting item failed to capture or the participants experienced a lapse of concentration. From "New Objects Dominate Luminance Transients in Setting Attentional Priority," by J. T. Enns, E. L. Austen, V. Di Lollo, R. Rauschenberger, and S. Yantis, 2001, Journal of Experimental Psychology: Human Perception \& Performance, 27, p. 1294. Copyright 2001 by the American Psychological Association. Reprinted with permission.

(1991a, 1992, 1994) and Folk et al. (2002) used an allocue paradigm and will, therefore, be discussed in the section on allo-cues below.

In Pashler's (1988) Experiment 6, participants were asked to search for a / among $O$ s, or vice versa, and to report which side of a display that was presented for $50 \mathrm{msec}$ contained the target shape. All the display elements were either red or green, with the exception of two items, which were the opposite color of the other display items. The presence of the uniquely colored items significantly decreased the participants' accuracy in detecting the shape singleton target. This would suggest that even though the color singletons were task irrelevant, they managed to capture the participants' attention. Ghirardelli and Egeth (1998) replicated and extended Pashler's results; in their experiments, participants likewise searched for a shape singleton target in a display that contained a color singleton distractor.

Difficulties in interpreting auto-cue costs. Strategic components. The irrelevant colored items in Pashler's (1988) Experiment 6 produced a decrement in target detection accuracy only when the exact nature of the target 
was not specified. When the participants knew the shape of the target in advance, the irrelevant colored item did not significantly impact the participants' performance. Either forcing or permitting the participants to restrict their attention to very specific target properties diminished the distracting influence of irrelevant color singletons (see also Folk et al., 2002; Theeuwes \& Burger, 1998). Ghirardelli and Egeth (1998), in an extension of Pashler's study, came to similar conclusions, using a unique texture patch as target and uniquely colored texture elements as distractors. The latter could either have the same shape as the elements making up the texture patch or not. Although both types of color distractors produced an elevation in RT to the target patch, this effect was attenuated when the color distractors differed in shape from the elements composing the target patch.

These results suggest that there is a top-down, strategic component in the "capture" of attention by feature singletons. Whenever the target properties are well defined, irrelevant distractors are largely ineffective in drawing attention to themselves. When there are a number of different alternatives for the singleton target on a given trial, irrelevant feature singletons draw attention to themselves. This pattern of results is consistent with participants' redefining their task as a search for any singleton whenever the target is not tightly specified. This strategy may be efficient because it allows search to be guided by the one property that is consistently known about the target: its singleton nature. Therefore, although the distracting singletons are nominally irrelevant, they are task relevant in the sense that they, like the target, are singletons (see Yantis \& Egeth, 1999). Whenever participants are provided sufficiently precise information about the target and search for any singleton is discouraged, they may adopt a strategy in which only items that match the target description are inspected. Bacon and Egeth (1994) have termed this strategy feature search mode. (The experiments that led them to postulate this search mode are described in the section on allo-cues below.)

An interesting facet of Pashler's (1988) Experiment 6 is that the color distractors always appeared in the same respective locations and the distractor locations were, therefore, known to the participants. Knowing the distractor locations did not eliminate the interference from the singleton distractors. This result is consistent with that of a study by Folk and Remington (1996), in which cuing of the distractor location did not eliminate the effect of the distractor. By contrast, knowing the target location in advance eliminates the potential of distractors to capture attention (Theeuwes, 1991b; Yantis \& Jonides, 1990), but only if the distractor is sufficiently far from the target (Theeuwes, 1991b) and participants are not engaged in a strategy that induces them to attend indiscriminately to any singleton item ${ }^{10}$ (Folk et al., 2002; see below). One interpretation of this pattern of findings is that knowing the distractor location does not eliminate capture because attention remains distributed widely across the display for (singleton) target detection (cf. Bravo \& Nakayama,
1992), whereas knowing the target location permits a narrowing of attention to the target location.

Filtering costs. The involvement of top-down strategies in the detection of singleton targets already poses problems for the contention that feature singletons capture attention in an involuntary fashion. Additional methodological concerns have been raised by Folk and Remington (1998), who have pointed out that demonstrating performance costs in paradigms that entail the presence of an additional object in the distractor-present displays (i.e., allo-cue with short SOA or auto-cue) may incur a generic object filtering cost (Treisman et al., 1983 ) that is dissociable from a spatial capture of attention. The evidence for such a filtering cost comes from the finding that a singleton distractor produces a general RT elevation (relative to a no-distractor baseline) independent of any cost associated with the relative spatial positions of the target and the distractors (Folk \& Remington, 1998, Experiments 2 and 3). This nonspatial RT cost makes it difficult to infer that attention was truly captured in any spatial sense from a mere increase in RT on distractor-present trials.

What remains unclear, however, is why filtering costs should be diminished or disappear entirely when the target properties are tightly specified, as in Pashler's (1988, Experiment 6) or Ghirardelli and Egeth's (1998) studies. Whether the distractor matches the target description or not, it still represents an additional object that needs to be filtered out. ${ }^{11}$ One could argue that filtering becomes more efficient when the filter can be more finely tuned to the target-defining properties, but more efficient filtering is filtering nonetheless. A similar question arises in connection with Theeuwes's (1994) Experiment 2: Here, the cost associated with an additional color singleton distractor disappears when the color singleton distractor is made less salient than the onset singleton target. Again, one could argue that the less salient distractor does not receive as strong an object representation as a more salient distractor and, hence, generates less of an objectfiltering cost. However, the fact remains that an additional object is present in the display and apparently does not produce a filtering cost. Finally, Theeuwes et al. (2000) examined the effect of a singleton distractor at various SOAs and found that only a distractor that was temporally sufficiently proximal (within $100 \mathrm{msec}$ ) to the target produced a slowing in RT. At all SOAs, there was an additional object in the display that would seem to require filtering, and yet no filtering cost was observed.

Theeuwes (1996) himself has argued against an account of his earlier results in terms of filtering costs on the basis of experiments in which he demonstrated a compatibility effect of the distractor on the RT to the target (see also Theeuwes, Kramer, \& Atchley, 2001). The assumption here is that, in order to produce a compatibility effect, the distractor needs to have been processed, which, in turn, requires a spatial shift of attention to the distractor. This spatial shift, however, is what Folk and Remington (1999) called into question: They argued 
that under conditions of low attentional load (as in Theeuwes's experiments), the distractor could easily have been processed without requiring a spatial shift of attention to the distractor. A more recent study by Theeuwes and Godijn (2002) revisited the issue of filtering costs. In this study, Theeuwes and Godijn used evidence of inhibition of return ${ }^{12}$ (IOR; Maylor, 1985; Posner \& Cohen, 1984) at the (allo-) cued location to argue that a shift of spatial attention had indeed occurred to the location of the singleton. This conclusion was based on the premise that IOR is inherently a spatial attentional effect and that IOR follows a reflexive shift of attention to the cued location. Theeuwes and Godijn contended that filtering costs could not explain the IOR they observed in their study.

Summary. In a number of studies, performance costs have been used in conjunction with auto-cues to investigate the ability of static singletons to capture attention. Although these studies provide a source of converging evidence for studies in which performance benefits have been used as an indication of capture, they are vulnerable to their own set of criticisms. One criticism concerns strategy artifacts to which auto-cues may be susceptible. Participants may, for example, adopt a deliberate strategy that allows them to be "captured" by any singleton in the display, whether it be the target or not (cf. Bacon $\&$ Egeth, 1994). Another potential confound is filtering costs, which may elevate RTs in the presence of a distractor but do not reflect a spatial capture of attention. One way to circumvent the problem of filtering costs may be to employ allo-cues with sufficiently long interstimulus intervals (ISIs), because the singleton target and the singleton distractor can be presented in separate displays, with an intervening temporal interval (and there is only a single object in each display, with no need to filter out an additional object). These types of studies will be discussed in the next section.

\section{Performance Benefits With Allo-Cues}

Allo-cuing has a long tradition in the study of attention and has received widespread popularity following Posner's (1980; Posner \& Cohen, 1984; Posner et al., 1982) seminal studies. In these earlier studies, the allocues consisted mainly of luminance transients (e.g., Jonides, 1981; Lambert \& Hockey, 1991; Müller \& Rabbitt, 1989; Posner \& Cohen, 1984; Posner et al., 1982). More recently, static feature cues have been used in allocuing as well. Among the features that have been examined are color (e.g., Chastain \& Cheal, 1998, Experiment 3; Folk \& Remington, 1998; Folk et al., 1992), shape (e.g., Theeuwes, 1990), and texture (e.g., Joseph \& Optican, 1996).

The benefits accrued by allo-cues have been examined in two important studies. First, Folk et al. (1992, Experiment 2) presented a cue display with a color singleton, followed by a target display with either a color singleton or an onset singleton target (see Figure 6). In separate blocks, the target either always appeared in the same location as the cue or never. When the target was a color singleton, the participants responded more quickly when the cue

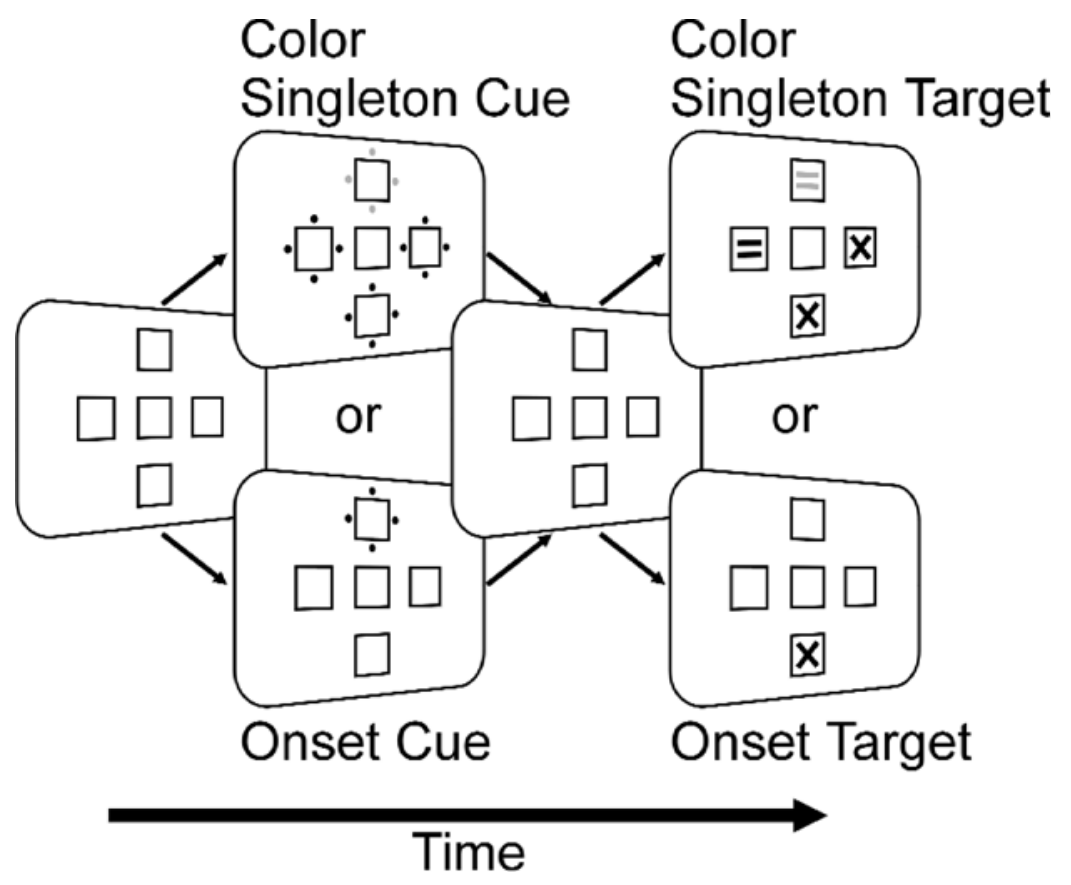

Figure 6. Example of the displays used by Folk, Remington, and Johnston (1992). A color target could be preceded by either an abrupt onset precue or a color singleton precue. Similarly, an abrupt onset target could be preceded by either type of precue. 
and the target were presented in the same location than when they appeared in disparate locations. This outcome suggests that under specific circumstances, a color allocue may capture attention. Second, using a similar design, Joseph and Optican (1996) showed that an orientation singleton (e.g., a vertical line among horizontal lines) is capable of capturing attention when participants are searching for an $L$ among upright $T$ s.

There are two difficulties with accepting either of these results as evidence for attentional capture by feature singletons. The first difficulty is that because the target in each case was a singleton, the singleton cues were only nominally irrelevant to the participants' task (cf. Yantis \& Egeth, 1999). The participants may have engaged in what Bacon and Egeth (1994) have termed singleton detection mode (see below), in which observers permit themselves to be attracted to any feature singleton, whether it be the target or the cue. Evidence for this possibility comes from Folk et al.'s (1992) Experiment 4 , in which a green singleton cue influenced participants' responses to a red target (see also Folk et al., 2002; Folk \& Remington, 1998, Experiment 1). Apparently, the crucial factor was whether the cue, like the target, represented a color singleton, not whether it matched the target-defining property. What complicates this explanation somewhat is the fact that when the participants were looking for an onset singleton, color singletons did not capture attention. To account for these somewhat inconsistent findings, Folk et al. (1992) proposed that participants are set to monitor a display for either static (e.g., color) or dynamic (e.g., onset or motion) discontinuities and that capture occurs within, but not between, these two classes of discontinuity.

The second difficulty is that, in both Joseph and Optican's (1996) study and Folk et al.'s (1992) Experiment 2 , the target and the cue shared the target-defining property. Therefore, even if the location of the cue was misinformative (Folk et al., 1992, Experiment 2) or uninformative (Joseph \& Optican, 1996) about the location of the target, a particular property of the cue (e.g., color or shape) was still highly informative in the sense that it was $100 \%$ correlated with the target-defining property. In Folk et al.'s (1992) Experiment 2, the redness of one of the items in the final display did not merely identify it as the target item, but first defined it as the target. In Joseph and Optican's study, both the target and the cue contained vertical and/or horizontal line segments, as has been pointed out by Yantis and Egeth (1999). Both Chastain and Cheal (1998, Experiment 3 ) and Yantis and Egeth (1999, Experiment 6) provided evidence that task relevance can strongly modulate the ability of an item to "capture" attention. Because of the dependence of capture on the match between the cue's and the target's features, Folk's paradigm has become known as the contingent capture paradigm.

Summary. Contrary to auto-cues, allo-cues are less vulnerable to an ambiguity about whether capture has truly occurred or whether the allegedly capturing item is merely placed first in the search cue. They furthermore permit a separation of the cue and the probe in time and space, whereas auto-cues do not. The temporal separation of cue and probe may allow the issue of filtering costs to be circumvented. At the same time, when using such a precue paradigm, one should remain cognizant of the fact that nominal irrelevance is not sufficient to draw conclusions about fully bottom-up, or stimulus-driven, capture (cf. Yantis, 1993b). (Whether true complete irrelevance can ever be achieved, of course, is an entirely separate issue.) The fact that capture, in tasks in which the cue is only nominally irrelevant, is contingent upon the observer's attentional control setting should not be seen as an immediate drawback. Rather, this circumstance makes the contingent capture paradigm a potentially fecund source of studies not directly related to attentional capture. In a study by Rauschenberger (2003), for example, the contingent capture paradigm was used to study the ontology of objects undergoing a change in luminance. (This study is discussed in detail below.)

\section{Performance Costs With Allo-Cues}

Apart from Folk et al.'s (1992) and Joseph and Optican's (1996), there have been other notable studies in which the question of whether feature singleton allo-cues capture attention have been pursued-operationalizing capture, however, as a performance cost, rather than as a performance benefit. Theeuwes (1991a), for example, found that the presence of an irrelevant color singleton elevated RTs to a shape singleton target. Similar RT costs occur with luminance (Theeuwes, 1991a) and form singleton (Theeuwes, 1991a, 1992) distractors. In a subsequent study, Theeuwes (1992) showed that practice did not permit participants to overcome the distraction effect of the irrelevant color singleton. However, the distraction effect was modulated by the relative salience of the target and the distractor singletons: Only if the distractor was sufficiently salient, did it produce an elevation in RTs (see also Theeuwes, 1991a, Experiment 3; Theeuwes, 1994, Experiment 2).

Using an interesting new approach to the question of whether color singletons capture attention, Folk et al. (2002) had participants perform a rapid serial visual presentation (RSVP) task, in which a target letter is imbedded in a stream of nontarget letters appearing at fixation. The target letter was defined by its unique color. At some point during the stream, an array of four irrelevant items appeared around the RSVP stream. These distractors were presented at various temporal intervals from the target: concurrent with the penultimate or the final letter in the stream before the target, simultaneous with the target, or concurrent with the first or second letter following the target (lags $-2,-1,0,1$, and 2, respectively). Four different distractor conditions were used: no distractor, all gray distractors, same-color distractor, and different-color distractor. In the same-color condition, one of the four distractor items had the same color as the target; in the different-color condition, one of the dis- 
tractors was uniquely colored but differed in color from the target. Folk et al. (2002, Experiment 1) found that both same- and different-color distractors produced an attentional blink $(\mathrm{AB})$ : That is, the participants were significantly less accurate at reporting the identity of the target letter at lags 1 and 2 when a color distractor was present than at other lags, seemingly because the peripheral singleton item captured attention away from the RSVP stream.

In Folk et al.'s (2002) study, an AB was obtained for different-color distractors only if the target was a uniquely colored item in a stream of homogeneously colored nontargets. No AB was observed with different-color distractors if the target was embedded in a stream of heterogeneously colored distractors. In the latter case, the target was defined by its unique color, but it did not represent a (temporal) color singleton. The participants, therefore, could not perform the task simply by monitoring the RSVP stream for any discontinuity but had to look specifically for an item that matched the target color. As before in Pashler's (1988) Experiment 6, the participants could engage in feature search mode.

Bacon and Egeth (1994) contrasted this mode of search with what they called singleton detection mode. In singleton detection mode, observers simply monitor the visual array for any singleton-perhaps because this represents a more economic strategy under some circumstances than does feature search mode. Experiments by Bacon and Egeth (1994) have provided support for the proposal that participants engage in either of these two modes of search, depending on whether mere singleton detection is possible or not. These experiments were similar in design to those of Theeuwes (1991a), in which a nominally irrelevant singleton captured attention. When it was possible for the participants to engage in singleton detection, Bacon and Egeth (1994) obtained results similar to those in Theeuwes (1991a): The singleton distractor appeared to capture attention. When, however, singleton detection was prevented by introducing several instances of the target (which was, therefore, no longer a singleton) into the display, a singleton distractor no longer captured attention. Consistent with this outcome, Lamy and Tsal (1999) showed that feature singleton distractors failed to produce capture when participants were searching for a conjunction target, rather than for a singleton target. In this case, singleton search was not a sensible strategy either, because the target was not a feature singleton.

Summary. Although in earlier studies in which allocues were used in combination with performance costs possible complications introduced by strategic components were not considered, more recent studies either have explicitly made these strategic components the object of study or have exploited them in imaginative ways. Exercising strict control over the types of strategies available to observers affords much greater clarity about how to interpret performance costs. As was concluded previously in the Performance Benefits With Allo-Cues section, when the potential pitfalls of allo-cues are taken into explicit consideration, this class of paradigms can prove to be a very fertile ground for the development of new and innovative studies, such as Folk et al.'s (2002). This particular quality of the allo-cue paradigm derives from the fact that the cue and the probe need not coincide in the same object, as with auto-cues.

\section{Preliminary Conclusions Concerning Feature Cues}

In summary, the evidence that feature cues, be they allo-cues or auto-cues, can capture attention in an involuntary, bottom-up fashion is somewhat unconvincing (cf. Gibson \& Jiang, 1998). Although feature cues have evidenced a potential to capture attention under some circumstances, all incidents of capture under these conditions have involved some implicit incentive to give attentional priority to the "capturing" item (cf. Yantis, 1993b; Yantis \& Egeth, 1999). The possible exception to this conclusion is the apparent capture of attention by large items and by luminous items (Yantis \& Egeth, 1999; see also Proulx, 2002). In the absence of evidence of capture across both allo- and auto-cue paradigms, and using both performance costs and benefits as an index of capture, the ability of size and luminance singletons to capture attention in an involuntary fashion is still pending confirmation.

\section{Motion}

Although technically not a feature cue in any narrow sense, a particular type of motion cue should probably be included in this section on static cues. An example of this type of cue is provided by Hillstrom and Yantis (1994, Experiment 1). In their experiment, one of the display items exhibited slight oscillatory motion, thereby setting itself apart from its background of stationary display items. This type of motion cue is "static" in the sense that its motion is continuous while the search display is on. It can be contrasted with a type of motion cue more appropriate to the next section. An example of this type of motion cue is provided by Franconeri and Simons (2003, Experiment 2). In their experiment, one of the display items started out at the periphery of the display and then, during the course of the trial, moved to join the other items on the perimeter of an invisible circle around fixation. At that point, all the items were unmasked, and the participant made a response. At the time at which search began, therefore, the motion item was indistinguishable from the no-motion items. The only thing that rendered it a singleton of sorts was its unique history in comparison with the other items. This type of cue will be treated in the next section.

As with luminance and color cues, there is no evidence from auto-cuing experiments that "static" motion cues can capture attention (Hillstrom \& Yantis, 1994). The only condition under which motion captures attention is if it serves to segment an object from its background and this object is then treated as a new perceptual object (see 
Hillstrom \& Yantis, 1994, Experiment 2). Hillstrom and Yantis have illustrated this effect with the example of the Geometridae moth found in northern Borneo. The moth often remains completely invisible when immobile, because of its camouflaging coloration. Once it moves, however, the moth is immediately segregated from its background and becomes conspicuous. It is not the motion of the moth per se that captures attention, but its sudden appearance to the observer's awareness.

Folk et al. (1994) examined the potential of motion to capture attention in an allo-cuing paradigm. On the basis of the results of Folk et al. (1992), they hypothesized that there should be within-category capture between onset and motion stimuli, because both represent instances of dynamic discontinuities. In their first four experiments, Folk et al. (1994) failed to find an effect of motion cues on the discrimination of either color or onset targets. The type of motion they used, however, could be characterized as "static" motion (see above); it is, therefore, perhaps not surprising, on the basis of the results from autocuing studies, that they failed to observe capture with their displays. In their fifth and final experiment, Folk et al. (1994) increased the salience of the motion cue and finally observed an effect of the motion cue with onset targets. The increase in salience, however, was achieved by using an apparent motion cue that alternated frames with two and four motion tokens, respectively. It is, therefore, conceivable that correspondence matching could be accomplished only for two of the motion tokens and that the other two were consequently perceived as abruptly appearing new objects. Furthermore, Folk et al.'s (1994) study faces the same problem as the other contingent capture studies: Because the "capturing" item is only nominally task irrelevant, it cannot be said to capture attention in a truly bottom-up fashion (Yantis, 1993b; Yantis \& Egeth, 1999). In summary, then, there is as little evidence for capture by motion cues as there is for any other type of static cue.

\section{Items With History: Attentional Capture by Dynamic Singletons}

Whereas feature singletons distinguish themselves from other items in the display by virtue of their static differences from these items, there is another class of singletons that are set apart from the other display items only by their unique history. Examples of the latter are onset singletons and change singletons. Onset singletons do not differ in appearance from those items in the final search display not having undergone an abrupt onset. What sets them apart is the fact that they were not present in the display before their onset-unlike the no-onset items, which were represented by placeholders. In the same way, it is possible to construct displays with all noonset items, in which one item undergoes a change in some featural dimension (luminance, color, etc.) but is indistinguishable from the other display items following its change. There are two ways in which this can be done. First, using homogenous displays, one can change one of the display items briefly and then change it back immediately before the onset of the final display (e.g., Yantis \& Hillstrom, 1994, Experiment 3). Second, one can use displays with heterogeneous no-change items and permanent changes to the change item. Although the modified item retains its new feature value, it does not represent a static singleton, because the final display is composed of a mixture of items that have the prechange value and items that have the new value (e.g., Enns et al., 2001, Experiment 2). A third class of stimuli can be produced by using displays with homogenous no-change items and permanent changes (e.g., Franconeri \& Simons, 2001, Experiment 8). This sort of hybrid design, although interesting in its own right, is somewhat problematic, because the potentially attention-capturing item is both a static and a dynamic singleton. ${ }^{13}$

\section{Performance Benefits and Costs With Auto-Cuing}

The most vigorously researched type of dynamic cue that has been investigated with the auto-cue paradigm is, perhaps, the new-object cue (e.g., Yantis, 1993a, 2000; Yantis \& Hillstrom, 1994), which is also referred to as the abrupt onset cue, on the basis of the language originally used by Yantis and colleagues to describe this type of cue (e.g., Jonides \& Yantis, 1988; Yantis \& Jonides, $1984,1990)$. The largest part of the present section is, consequently, dedicated to new-object cues, reflecting their prominent position in the literature.

Yantis and colleagues have argued for the ecological significance of attentional capture and have suggested that the automatic orienting response elicited under the proper circumstances has adaptive value (Rauschenberger \& Yantis, 2001; Yantis, 1993a, 2000; Yantis \& Hillstrom, 1994). A more recent formulation of this argument by Franconeri and Simons (2003), the behavioral urgency hypothesis, adheres to the notion that certain events capture attention because of their ecological significance but it dispenses with the claim that only new objects capture attention.

According to the behavioral urgency hypothesis, only events that may require an immediate response elicit an involuntary shift of attention. From this formulation, it should become apparent that the new-object hypothesis represents a special case of the behavioral urgency hypothesis: New objects represent just one example of stimuli that may require an immediate response, because they might constitute either predator or prey (Cole, Gellatly, \& Blurton, 2001; Franconeri \& Simons, 2003; Rauschenberger \& Yantis, 2001; Yantis, 1993a, 2000; Yantis \& Hillstrom, 1994). At the same time, the behavioral urgency hypothesis also invites a reformulation of Folk et al.'s (1992) framework, which proposes that observers may be set by default for the appearance of new objects: It is possible that, instead, observers are set by default for urgent events and that such events therefore capture attention. The precise relationship between the behavioral urgency hypothesis, the new-object hypothe- 
sis, and Folk et al.'s (1992) framework remains to be fleshed out in more detail.

New objects and luminance transients. The investigation of onset cues can be traced back to J. T. Todd and Van Gelder (1979), who first developed the method, still used widely today, of creating a contrast between onset and no-onset by premasking the no-onset items. Although J. T. Todd and Van Gelder developed this method to study eye movements, Yantis and Jonides (1984) have adapted J. T. Todd and Van Gelder's procedure for the study of covert shifts of attention. What Yantis and Jonides (1984) found was that responses to onset items were not influenced by the number of nontargets in the display, whereas RTs to no-onset items increased with each additional nontarget. This preferential processing of onset items in search was attributed first to the luminance transients that accompany their appearance (cf. Yantis \& Jonides, 1984). The attribution of capture to the luminance transients was not unreasonable, on the basis of the suspected relationship between automatic orienting and transient channels in the visual system (e.g., Breitmeyer \& Julesz, 1975; Lennie, 1980; Nakayama \& Mackeben, 1989; Phillips \& Singer, 1974; Singer \& Phillips, 1974; J. T. Todd \& Van Gelder, 1979), which are thought to mediate rapid automatic responses.

However, Yantis and Hillstrom (1994) found luminance transients to be neither necessary nor sufficient to produce attentional capture. At the same time, though, luminance changes appear to be sufficiently salient to produce pop-out when participants are deliberately searching for them in an allo-cuing task (Theeuwes, 1995a). Using a psychophysical approach more sensitive to the known neurophysiology of the transient channels in the visual system, Nakayama and Mackeben (1989) came to the same conclusion that the automatic orienting of attention is not mediated by these early transient channels. With single-transient (allo-) cues, Nakayama and Mackeben observed a brief enhancement of performance, followed by a rapid decline. They obtained the same transient performance enhancement with flickering stimuli, even though it is known from neurophysiology that early transient channels exhibit a sustained response to such continual stimulation.

As an alternative to the luminance transient account, Yantis and Hillstrom (1994) proposed that the appearance of a new perceptual object is what captures attention (see also Hillstrom \& Yantis, 1994; Yantis, 1993a, 1998, 2000; Yantis \& Gibson, 1994; Yantis \& Jonides, 1996): Whenever a new object file is created (cf. Kahneman \& Treisman, 1984; Kahneman, Treisman, \& Gibbs, 1992; Wolfe \& Bennett, 1996), an attentional interrupt is signaled, and attention is summoned to the new object (Yantis \& Hillstrom, 1994, p. 96). Yantis and Gibson made the interesting observation that a new object file is apparently also created when a previously existing object disappears for more than $100 \mathrm{msec}$ and then reappears. This finding places the emphasis on the perceptual newness of the object, rather than on its newness as an object in a more episodic sense. Evidence from visual search suggests that the perceptual newness of an object has a limited lifetime. From their results with multiple abrupt onset items, Yantis and Johnson (1990) and Yantis and Jones (1991) concluded that approximately four onset items are processed before search turns to any noonset items (within about $100 \mathrm{msec}$; Yantis, 1993a). The limiting factor appears to be the number of onset items that can be serviced before their newness, or at least their priority in search, fades (Yantis, 1993a; Yantis \& Jones, 1991).

The new-object account represents a strong departure from the low-level luminance transient explanation (cf. Irwin, Colcombe, Kramer, \& Hahn, 2000; Thomas \& Luck, 2000; Yantis \& Jonides, 1984), in that capture is mediated no longer by rather crude signals from peripheral receptors, but by higher level object representations. To test the new-object account, Yantis and Hillstrom (1994) used new objects that were equiluminant with respect to their background and found that these still captured attention even though there were no attendant luminance transients. Although Yantis and Hillstrom's methods of creating equiluminant objects have been criticized, their results have by and large been replicated (see Gellatly, Cole, \& Blurton, 1999). The fact that equiluminant new objects capture attention is all the more remarkable because, for example, color changes to old objects do not pop out at equiluminance (Theeuwes, 1995a). When these color changes precipitate the appearance of a new object, attention is captured even though the color changes themselves may go unnoticed.

At least two other studies have contrasted luminance changes with new-object onsets. Enns et al. (2001) pitted polarity change items directly against onset items. The polarity change items underwent a luminance change from below the background luminance level to above the background level (black to white, on a gray background) or vice versa (white to black). The appearance of the onset items, by contrast, entailed only a luminance change from the background luminance level to a level either above or below that of the background-by some measure, therefore, only half the luminance change as that of the polarity change items. Despite this "disadvantage" in terms of the magnitude of luminance change, onset items were significantly more successful at guiding search than were polarity change items. The only exception to this rule occurred when the no-onset items experienced both a polarity and a contrast change. Enns et al. argued that this sort of change is ecologically implausible and, therefore, attracts attention.

Similar results, although obtained in an allo-cue paradigm, were observed by Rauschenberger and Yantis (2001), who found capture by a new subjective object (a Kanizsa square). Although such subjective objects are perceived as brighter than their physically equally luminous surround (e.g., Halpern, 1987), this brightness contrast is merely inferred. (It is not contained in the physical stimulus itself.) One would be hard pressed to 
explain Rauschenberger and Yantis's results with any sort of low-level luminance transient account, because the latter rely on the stimulation of peripheral mechanisms sensitive to transients. No physical transients accompany the onset of the subjective square in Rauschenberger and Yantis' experiments, however. ${ }^{14}$

Although new-object onsets are, in principle, dissociable from luminance transients, this does not preclude interactions between the two. For example, Miller (1989) and later, following up on his study, Martin-Emerson and Kramer (1997) examined the influence of simultaneous offset transients on attentional capture by abrupt onsets. The offset transients were created by the removal of line segments in the placeholders for the no-onset items. These offset transients have usually been present in attentional capture paradigms modeled after that in J. T. Todd and Van Gelder (1979). However, Miller and MartinEmerson and Kramer increased the number of offset transients to exceed the number usually present in these experiments. With a larger than usual number of offsets, onsets no longer reliably captured attention in either study. Similar effects can be achieved by abruptly altering the background of a search display simultaneously with the onset of the new object (Grandison, Vaughan, \& Yantis, 1997). Watson and Humphreys (1995) have examined the ability of offset transients of the type used by Miller and by Martin-Emerson and Kramer to capture attention in an involuntary fashion. They concluded that while offset transients can be detected very efficiently when observers are set to look for them, they do not capture attention (but see Theeuwes, 1991b, Experiment 2). It appears, then, that although transients are in general not capable of capturing attention, they do interfere with attentional capture by new objects. Why this should be so is still an open question.

Other than luminance transients, top-down knowledge of the target's location can prevent a new object from capturing attention as well. Yantis and Jonides (1990, Experiment 2) used endogenous spatial cues to inform their participants about the location of the target prior to its appearance. Given sufficient time to focus their attention on the prospective target location, the participants became immune to the effects of abruptly appearing new objects (see also Juola, Koshino, \& Warner, 1995; Koshino, Warner, \& Juola, 1992).

Challenges to the new-object account. The claim that perceptually new objects capture attention has not gone unquestioned. One set of criticisms is perceptual in nature, the other attentional. (The latter will be discussed in the following section on allo-cues.) Gibson (1996a, 1996b) has contended that onset items enjoy preferential processing not because they draw attention, but because their visual quality is superior to that of no-onset items. This claim attaches itself to the procedure used by Yantis and Jonides (1984) of gradually unveiling the noonset items. Gibson (1996a, 1996b) argued that because the no-onset items are premasked, their visual quality is degraded by forward masking due to the visual persis- tence of the placeholders. He supported this contention by showing that displays with all onset items are responded to more quickly than displays with all no-onset items. Yantis and Jonides (1996) offered a different interpretation of these results. According to their proposal, the updating of object files is slow, whereas their creation is fast and attracts attention. The difference in RTs to old- and new-item displays is a function of this difference, which is related to the maintenance of object files, not to the visual quality of the stimuli. This conclusion is corroborated by Gellatly and Cole (2000), who used second-order motion-defined stimuli, which do not present the problem of forward masking by placeholders. Under conditions in which forward masking of the type envisioned by Gibson (1996b) did not occur, Gellatly and Cole still observed an advantage of new objects over old objects. Yantis and Jonides (1996, Experiment 2) took a different approach and eliminated the possibility of forward masking by setting the display items into (apparent) motion. Both the onset and the no-onset stimuli now appeared in previously blank locations. Responses to onset targets remained faster than those to no-onset targets.

Other types of dynamic cues. In addition to new objects, other types of dynamic auto-cues have been considered as candidates for attention-capturing stimuli. Like new objects, these cues represent singletons only insofar as their history deviates from that of the other display items. Enns et al.'s (2001) study has already been discussed as an example. In this study, the critical item underwent a change in polarity relative to the background. Once it had undergone its change, it was indistinguishable from the other display items. Enns et al. found no evidence that contrast polarity change singletons capture attention. The only exceptions were items that underwent both a polarity and a contrast change. As Enns et al. argued, this type of change may lack ecological plausibility. I shall return to this point.

Slightly different results were obtained by Franconeri and Simons (2001), who investigated a large array of different types of transformations. In their color change experiment, which was modeled after Yantis and Jonides's (1984) experiments, Franconeri and Simons (2001) observed shorter RTs when the target happened to be a color change item than when it happened to be one of the no-change items. Because search slopes were relatively steep (27 msec/item), it is likely that capture occurred only on a subset of trials. Using allo-cues, Theeuwes (1990), whose experiments will be described in more detail below, failed to find capture by color change cues. Franconeri and Simons's (2001) experiment differed from Theeuwes's (1990) in that the color change rendered the change item unique in appearance. It is conceivable that color singletons and color changes do not attract attention by themselves but that the combination of the two does capture attention. Why this should be so is not clear, though, and the issue calls for a more systematic exploration. 
Other experiments by Franconeri and Simons (2001, 2003 ) were dedicated to examining motion. Contrary to the continuous motion used by Hillstrom and Yantis (1994), the motion used by Franconeri and Simons (2001, 2003) occurred before the onset of the search display and did not continue to distinguish the motion item after search commenced. Under these conditions, an item that had moved into its final position was responded to more quickly than an item that had remained stationary during the entire trial, although slopes were once again too steep to suggest true capture (see also Hillstrom \& Yantis, 1994, pp. 404ff.). Franconeri and Simons (2001, 2003) found that the distance across which an item traveled modulated the "capture" effect: Items that had traveled a short distance produced "capture," whereas items that had traversed a longer distance did not. ${ }^{15}$ However, when the long-distance motion item passed behind an occluder, even it produced “capture." Yantis and Gibson's (1994) findings make it unlikely that the occluded item was treated as a new object after its reappearance. First, it disappeared too briefly $(<100 \mathrm{msec}$; $\mathrm{cf}$. Yantis \& Gibson, 1994); second, the occluder would have reinforced the spatiotemporal continuity of the item undergoing occlusion (cf. Yantis, 1995). Although it is not entirely clear how these results should be interpreted overall, they do represent a slight contrast to Hillstrom and Yantis's claims. The two studies could possibly be reconciled by suggesting that the entire homogeneous display of placeholders in Franconeri and Simons's $(2001,2003)$ studies was treated as a single object (Bravo \& Nakayama, 1992; Nakayama, 1990) and that the motion of the one item served to individuate this item (cf. Hillstrom \& Yantis, 1994).

Most studies in which the ability of motion to capture attention has been examined have used either translational or rotational motion (e.g., Folk et al., 1994; Franconeri \& Simons, 2003, Experiments 2.1 and 2.2; Hillstrom \& Yantis, 1994). In the natural world, though, most motion of this sort would appear to be uninteresting from the survival perspective of an animal. Of greater interest are, presumably, the motion of a potential aggressor toward an animal or the motion of potential prey away from the animal. Both infants (e.g., Nanez, 1988; Nanez \& Yonas, 1995) and animals (e.g., Hassenstein \& Hustert, 1999; Schiff, Caviness, \& Gibson, 1962) are known to respond to looming objects. Franconeri and Simons $(2001,2003)$ took this fact as a cue to investigate the ability of looming and receding stimuli ${ }^{16}$ to attract attention to themselves. They found evidence of capture with looming, but not with receding, stimuli (however, see Hillstrom \& Yantis, 1994, Experiment 1; see also King, Dykeman, Redgrave, \& Dean, 1992). To explain these contrasting results, Franconeri and Simons (2003) proposed that only looming, but not receding, objects hold any interest for an animal's survival.

Assessment. The evidence available from auto-cuing suggests that new objects capture attention in a largely involuntary fashion but that capture can be diminished or abolished altogether by foreknowledge of the relevant tar- get location. The evidence for most other dynamic autocues is more equivocal. Franconeri and Simons's (2003) experiments using motion, however, are suggestive. New objects may represent only a special case of behaviorally urgent events (such as looming objects; Franconeri \& Simons, 2001, 2003; see also note 17) that capture attention because of their need for immediate attention.

Summary. Auto-cues haven proven to be a very successful medium for studying dynamic cues-in particular, new-object cues. The most significant methodological issue that arises with this paradigm when dynamic cues are studied is that the dynamic nature of the cue may imply a permanent change in the dynamic cue. Depending on the composition of the display, this change in the cue has the potential of rendering the cue a feature singleton. As was discussed earlier, there are a couple of solutions to this problem. One is to use heterogeneous displays, so that the cue is a singleton neither before the change occurs nor after. The other, if homogenous displays are used, is to have the cue revert back to its original appearance after a transient change. Regardless of which approach is used, dynamic cues that entail the modification of a display item give rise to additional issues of a theoretical nature. The Large Changes and New Objects section below is dedicated to these issues.

A concern that has been raised in particular about new-object auto-cues by Theeuwes (1995a) is that the new object may "pop out" of the display because participants notice that a previously unoccupied location is now filled, following the abrupt onset. This account seems to suggest an almost overt strategy. What speaks against this memory explanation is the fact that, on the basis of interviews during debriefing, Yantis's participants were rarely aware of the abrupt onset items (see Yantis, 1993b, note 2). Anecdotally, at least, evidence for a memory of previously unoccupied locations is lacking, therefore. Furthermore, it is not clear why memory for location should afford a more successful strategy than memory for other changed features. If efficient search is mediated by a comparison between pre- and post-onset displays (cf. Theeuwes, 1995a), such a comparison should be equally possible with other types of dynamic displays (e.g., color change).

\section{Performance Benefits and Costs With Allo-Cuing}

Abrupt onsets. Both the first impetus for considering the possibility of capture by abrupt onsets (e.g., Jonides, 1981) and perhaps the strongest evidence that onsets capture attention (Jonides, 1981; Remington, Johnston, \& Yantis, 1992) have come from allo-cuing paradigms. Most of these paradigms involve the brief flashing of bright cue dots, bars, or arrows (e.g., Chastain \& Cheal, 1998, 1999b; Folk et al., 1992; Jonides, 1981; Juola et al., 1995; Koshino et al., 1992; Nakayama \& Mackeben, 1989; Remington et al., 1992; Warner et al., 1990). Typically, the abrupt appearance of these cues interferes with the detection or discrimination of 
the target (e.g., Chastain \& Cheal, 1998, 1999a; Folk et al., 1992; Jonides, 1981; Juola et al., 1995; Koshino et al., 1992; Remington et al., 1992; Warner et al., 1990). This is the case even when the cue indicates the correct target location only on a proportion of the trials corresponding to chance (e.g., Folk et al., 1992, Experiment 3; Jonides, 1981, Experiment 2) or less than chance (Warner et al., 1990, Experiment 1) or when the cue never indicates it (Remington et al., 1992). This finding has been taken to demonstrate that abrupt onsets capture attention in an involuntary fashion (Remington et al., 1992). It complements the results obtained with auto-cues (e.g., Rauschenberger \& Yantis, 2001, Experiment 5; Theeuwes, 1994).

In most of these experiments, however, both the distracting event and the event to which the participants responded (the abrupt appearance of the target) were of a like nature. The cue and the probe both represented singletons that were characterized by their abrupt onset. The participants may, therefore, have engaged in singleton detection (cf. Bacon \& Egeth, 1994), and furthermore, their attentional set may have included the attention-capturing cue (see Yantis, 1993a). Although the finding that performance is disrupted by a largely or completely misleading cue is an impressive result, its persuasiveness is diminished by the potential involvement of top-down factors. Precisely the exclusion of these factors was what allowed Yantis (1993a, 1993b, 1998; Yantis \& Egeth, 1999; Yantis \& Hillstrom, 1994) to conclude that the abrupt onset of a new object captures attention in a stimulus-driven fashion. Experiments such as those conducted by Warner et al. (1990; also Juola et al., 1995; Koshino et al., 1992) have partially avoided these problems by using a target that was not a singleton. Because the defining attribute of the target was not shared by the cue, the conditions for true bottom-up capture were given (see Yantis, 1993b). Even with targets that were not onset singletons, the effect of the cue persisted. However, these findings remain vulnerable to the criticism that the participants may have been set for the onset of the target display and an onset cue therefore captured attention (cf. Gibson \& Kelsey, 1998).

A set for display-wide features. This criticism was developed in response to new-object capture experiments, in an attempt to dilute the claim that capture by abrupt onsets is purely bottom-up or stimulus driven. Gibson and Kelsey (1998) contended that the onset of a new object may capture attention because observers are prepared for the abrupt onset of the entire display (see also Johnson, Hutchinson, \& Neill, 2001). The abrupt onset of the search display typically signals the presence of the target in a very general sense. Hence, participants presumably adopt an attentional set for abrupt onset, which is satisfied by the abrupt onset item. The claim that new objects capture attention in a bottom-up fashion rests on the assumption that participants do not adopt any particular attentional set in experiments modeled after Yantis and Jonides (1984), because abrupt onset is neither a target- defining nor a reported attribute (see Yantis, 1993b). Gibson and Kelsey's argument undermines precisely this assumption, because participants may be set for the property that distinguishes the abrupt onset item: When the latter captures attention, this is an instance of contingent capture (cf. Folk et al., 1992), rather than a pure form of bottom-up capture.

Gibson and Kelsey's (1998) account is somewhat akin in spirit to Folk et al.'s $(1992,1993)$ proposal that observers are set for onsets by default whenever there is no reason to adopt any particular attentional set. So far, Gibson and Kelsey's claims have remained uncontested (see, however, Johnson et al., 2001). They appear to rest quite comfortably with the current opinion in the literature that a complex interaction of stimulus-driven and goal-directed factors underlies attentional capture (see Folk et al., 1992; Rauschenberger \& Yantis, 2001; Yantis, 1998, 2000). Gibson and Kelsey's conclusions, however, were drawn from an allo-cuing paradigm; the application of these conclusions to auto-cuing paradigms, such as the ones used by Yantis and colleagues, is, therefore, currently based on an analogy. Also, Gibson and Kelsey used all-onset displays (cf. Gellatly \& Cole, 2000; Gibson, 1996b). Although a distinct possibility, it remains to be seen whether the same effects would obtain with premasked displays (cf. J. T. Todd \& Van Gelder, 1979; Yantis \& Jonides, 1984) and chance validity (see Yantis, 1993b) — the conditions under which capture by new objects has been established.

Interfering with capture. Given these unknowns, the question of whether top-down factors are responsible for capture by abrupt onset cues must remain controversialfor the time being, at least. What is less controversial is that top-down factors certainly do modulate the potential of a new-object cue to capture attention, once capture is established. As with onset auto-cues, practice can diminish the ability of an onset allo-cue to capture attention. In a study by Warner et al. (1990), practice resolved the conflict between a valid endogenous cue and an invalid exogenous cue in favor of the endogenous cue. Without practice, the participants found it difficult to resist the lure of the abrupt onset cue even when it indicated the position of the target on only $20 \%$ of the trials while the endogenous cue indicated the target's position on $80 \%$ of the trials. After some experience with the task, the participants were able to take advantage of the predictive validity of the endogenous cue and ignore the exogenous cue. ${ }^{17}$

Similarly, an attentional set for anything other than abrupt onset will prevent an onset allo-cue from attracting attention to itself. In Experiment 1 of Folk et al. (1992), an onset distractor failed to impact the participants' performance when the target was a red feature singleton. Folk and Remington (1999) determined that this was the case regardless of whether the onset consisted of a luminance transient or the appearance of a new perceptual object. In a related experiment, Atchley, Kramer, and Hillstrom (2000, Experiment 1) paired onset cues 
with offset targets and failed to observe an effect of the cue on the participants' responses to the target. Capture was reinstated only when the participants were set for both onset and offset transients (Atchley et al., 2000, Experiments 2 and 3). However, now, not only onset cues captured attention, but also offset cues when the target was defined by onset (see also Pratt, Sekuler, \& McAuliffe, 2001, Experiment 1).

These failures of abrupt onset allo-cues to capture attention parallel Yantis and Jonides's (1990) findings with abrupt onset auto-cues. Theeuwes (1991b, Experiment 1) has extended Yantis and Jonides's (1990) results by examining the effect of the distance between the onset and the target, which is possible only with allo-cues. For onsets spatially separated from the target, RTs were not affected, provided that the participants had sufficient time to focus their attention. By contrast, onsets close to the target impacted RTs even when the participants had ample time to focus their attention. In summary, then, practice, knowledge of the target location, and/or knowledge of the target-defining feature(s) can all prevent abrupt onsets from capturing attention.

Contingent capture. In Yantis and Jonides's (1990) and Theeuwes's (1991b) experiments, participants were given highly task-relevant information about the location of the target. Under these conditions, the ecological role of new perceptual objects is considerably diminished. Yantis and Jonides (1990) argued that the relinquishing of attentional control to the organism under such conditions is highly adaptive in that it prevents otherwise attentiondemanding events from interfering with the organism's current overriding goals (see also Rauschenberger \& Yantis, 2001). Either when the precise location of the task-relevant event is known in advance (and all other locations temporarily become irrelevant) or when the defining features of the task-relevant object are known (and all other features hence become irrelevant), abrupt onsets lose their behavioral significance. Folk et al.'s (1992) results may constitute another example of the finding that attentional capture by abrupt onsets can be overridden when participants are in full possession of all the relevant information necessary to accomplish their task successfully.

Indeed, Folk et al.'s (1992) results may recapitulate two distinct phenomena already known from other studies: First, abrupt onsets fail to capture attention when participants have tightly circumscribed behavioral goals (cf. Theeuwes, 1991b; Yantis \& Jonides, 1990); second, singletons other than new-object singletons will begin to capture attention when participants are given an incentive to attend preferentially to these singletons (cf. Bacon \& Egeth, 1994; Yantis, 1993b). The symmetry of Folk et al.'s (1992) design may be distracting from the fact that underlying their apparently symmetrical results are two separable phenomena. Perhaps contingent capture is not a unitary phenomenon at all but, rather, a conflation of two distinct phenomena into a single paradigm.

More subtle measures of capture. Recent evidence suggests that the symmetry of Folk et al.'s (1992) results cannot go entirely unquestioned. Gibson (1999), for example, has conducted a fine-grained analysis of data from a direct replication of Folk et al.'s (1992) Experiment 1 . This analysis suggests that the onset cues in Folk et al.'s (1992) experiments may have captured attention after all, but that this effect was too subtle to be detected by Folk et al.'s (1992) analysis (Gibson, 1999). One reason Folk et al.'s (1992) experiments might not have been sensitive to the effects of the onset cue is that they were based on an allo-cue paradigm with a greater than zero cue-probe SOA (100 msec). Recall from the discussion of the merits and drawbacks of allo-cues that this type of paradigm, when used with longer SOAs, may not be appropriate for onset cues, because the effect of the cue may have dissipated by the time the probe is presented. Although the SOA in Folk et al.'s (1992) experiments may have been chosen ideally for the color cue, it may have been subideal for the onset cue.

Similar conclusions are suggested by studies in which IOR has been used as an index of capture. In a study in which the effects of practice on capture (albeit using abrupt luminance changes instead of new objects) were examined, Lambert, Spencer, and Mohindra (1987) provided their participants both with explicit instructions to ignore onsets and with practice in doing so. Under these conditions, they found that an unpredictive onset cue no longer produced an RT benefit when it happened to coincide with the target location but that the costs observed at longer SOAs (i.e., IOR) persisted even after practice. One possible interpretation of these results is that indirect measures of involuntary attentional capture (i.e., IOR) continue to reveal effects even when more direct measures fail.

Exploring the role of attentional set in IOR, Pratt et al. (2001) and Gibson and Amelio (2000) used a modified version of Folk et al.'s (1992) paradigm that included long cue-target SOAs. Consistent with Folk et al.'s (1992) results, both studies showed contingent capture at short SOAs; that is, color cues captured when paired with color singleton targets, and onset cues captured when paired with onset targets. At long SOAs, however, only onset cues, but not color singleton cues, produced "contingent" IOR. This finding led both Pratt et al. and Gibson and Amelio to conclude that capture, in the case of the color cue, was mostly the consequence of endogenous control. Gibson and Amelio concluded that abrupt onsets "appear to play a special role in eliciting inhibition of return" (p. 502). In a related study, Oonk and Abrams (1998) observed IOR even with equiluminant new objects, underscoring these conclusions. Taken together, these findings somewhat erode the ostensible symmetry in Folk et al.'s (1992) paradigm.

Assessment. Folk et al.'s (1992) contingent capture paradigm has established itself firmly in the literature on capture. It provides a compelling demonstration of the vulnerability of attentional capture to top-down influences. More recent studies (Gibson, 1999; Gibson \& Amelio, 2000; Pratt et al., 2001), however, have raised the possibility that Folk et al.'s (1992) paradigm might 
not have been sufficiently sensitive to the ability of abrupt onsets to capture attention. Given the availability of potentially more sensitive measures, it may be desirable to augment our current measures of capture with these more sensitive measures.

Ultimately, the question of how to interpret the results from Folk et al.'s (1992) experiments reduces to a matter of personal conviction. There is little debate over the conclusion that certain task-relevant information can either prevent capture (e.g., Folk et al., 1992; Theeuwes, 1991b; Yantis \& Jonides, 1990) or provide incentives for participants to allow their attention to be drawn to singleton items (e.g., Bacon \& Egeth, 1991). However, whether such contingent capture ubiquitously reflects attentional control settings (cf. Folk et al., 1992, 1993) or whether it is elicited only by certain experimental designs (Yantis, 1993b) will continue to remain a contentious issue. Folk et al.'s (1992) account of their own data has the advantage of being parsimonious, because it postulates a single mechanism (attentional control settings) to explain both sets of results (i.e., capture in one case and failure to capture in the other). The alternative interpretation presented above (top-down interference with capture in one case and top-down incentives for "capture" in the other), however, is equally consistent with what is known about attentional capture. Because both accounts rely heavily on the idea of control settings, the tension between the two accounts may be mostly of a semantic nature: It revolves around the question of how to define attentional capture and whether Folk et al.'s (1992) definition is sufficiently stringent (cf. Yantis, 1993b).

Other dynamic allo-cues. Apart from the abrupt onset of new objects, dynamic cues that have been examined using allo-cues include luminance transient cues (where an existing object abruptly changes its luminance; e.g., Atchley et al., 2000), color and shape changes (e.g., Theeuwes, 1990), combined luminance and color transient cues (e.g., Lambert \& Hockey, 1991), and motion cues (e.g., Folk et al., 1994). Theeuwes (1990) used displays in which one item changed abruptly in either its shape or its color $260 \mathrm{msec}$ after the onset of the search display. As a consequence of this transformation, the change item mutated from a singleton into a nonunique display item, rendering it physically indistinguishable from the other items in the display. In Experiments 1 and 2, Theeuwes (1990) established that uniqueness per se did not confer a benefit to unique items. In Experiment 3, Theeuwes (1990) showed that when the same unique items changed their shape abruptly, search was more efficient for those items than for those that had not undergone a change, even though both differed only in their respective histories (see also Krumhansl, 1982; Yantis \& Jonides, 1984,pp. 604 and 618). Theeuwes (1990) estimated that capture occurred on only $25 \%$ of all trials. By contrast, Yantis and Jonides (1984) estimated that attention in their experiments was captured by the onset item on $90 \%$ of the trials. In his final ex- periment, Theeuwes (1990) failed to find any evidence of capture by an abrupt change in color.

Some of the first studies in which the automatic capture of attention was examined used cues abruptly changing in luminance, rather than new-object cues (e.g., Posner \& Cohen, 1984; Posner et al., 1982). In all of these studies, the participants were looking for the onset of a target, which was always accompanied by a luminance transient. The participants may, therefore, have been set for luminance transients, and the cues produced contingent capture (Yantis, 1993a). Studies by Atchley et al. (2000) and Folk et al. (1994) have indicated, however, that the solution may not be that simple. In the study by Atchley et al. (2000, Experiment 4a), the participants were explicitly set for luminance transients, and yet luminance change cues did not necessarily produce evidence of capture. Why luminance transients should capture in one case, in which the participants may have been set for transients, but not in the other, in which they were explicitly set for transients, is not immediately apparent. In the study by Folk et al. (1994), participants were set for abrupt onset, color, or one of two types of motion. Although abrupt onset and motion both represent dynamic discontinuities, motion cues failed to produce an effect on abrupt onset targets. In this respect, onset targets behaved just like the color targets. Only in the last of five experiments did motion cues begin to yield contingent capture with onset targets. As was discussed earlier, however, the motion cues in this experiment may have comprised apparent motion and new-object components. In sum, therefore, it is not clear that the featural changes in the earlier experiments with allo-cues necessarily captured attention only because the participants were set for these featural changes or were in singleton detection mode.

Irwin et al. (2000) contrasted luminance and color changes with the appearance of new objects. They interpreted Hillstrom and Yantis (1994) as rejecting the possibility that certain changes to old objects may precipitate the creation of a new object file: "According to Yantis and Hillstrom (1994), changing the luminance of an existing object does not constitute the creation of a 'new' object, so by their account onset distractors should capture attention but luminance increments should not" (Irwin et al., 2000, p. 1454; see also Kahneman \& Henik, 1981; Yantis \& Hillstrom, 1994, p. 106). Contrary to this prediction, Irwin et al. (2000, Experiment 3 ) found capture by luminance change items. The difficulty with accepting these results as evidence for capture by luminance change items is that the singleton target was defined by a luminance increment. Not only, therefore, were the participants likely in singleton detection mode, but in addition, they were set for luminance transients. Irwin et al.'s results can, therefore, serve as another instance of contingent capture. Indeed, Atchley et al. (2000, Experiment 4) have recently shown that a sufficiently large luminance transient can capture attention when participants are set for a luminance transient target (see also Chastain \& Cheal, 1999b). 
Assessment. The literature reports occasional incidents in which a dynamic cue other than a new-object cue appears to have captured attention. Theeuwes (1990), for example, observed that shape changes captured attention. The proportion of trials on which capture occurred in Theeuwes' (1990) study, however, was low in comparison with what is customarily found with new-object cues (25\% vs. 90\%). Apart from shape change, it has been suggested that luminance change captures attention (cf. Irwin et al., 2000). In all of the reported examples of successful capture, however, the participants were likely set for luminance change.

Summary. Indeed, this appears to have been the case in most studies in which featural changes have been examined for their ability to capture attention. This problem was particularly pronounced in older studies in which dynamic allo-cues were used (traditional cuing experiments), because it had previously gone unrecognized that the onset of the cue belongs to the same class of event as the appearance of target (cf. Yantis, 1993a). An appreciation of this fact was, perhaps, first permitted by the results of Folk et al.'s (1992) seminal study, which brought about an awareness of the possible involvement of top-down factors in attentional capture. The lesson to be learned from this study is that one should always be mindful of the potential confound of unintended incentives to orient preferentially to what is ostensibly a neutral target. One solution suggested above is to use a target that is not a singleton, because such a nonsingleton target will no longer permit guidance based on a top-down set. A more sensible approach, however, may be to shift the emphasis from the question of what captures attention to what prevents the capture of attentional capture. This approach leaves more contentious issues aside for the time being and carries the promise of great benefits for applied psychology: As the demand on our attentional "resources" increases steadily in modern society, finding ways of preventing the diversion of attention under hazardous conditions may prove to be vital.

An equally fundamental issue in regard to dynamic cues is the ambiguity in the interpretation of their ontological status. As was mentioned earlier, it is not clear whether a cue undergoing some featural change (e.g., luminance or color change) is interpreted by the visual system, following change, as a modified object or as a new object. If it has been interpreted as a new object, capture, in cases in which dynamic cues have successfully elicited an involuntary shift of attention, may have been due to (what was interpreted as) the appearance of a new object, rather than to the change per se.

\section{Large Changes and New Objects}

The study by Atchley et al. (2000), mentioned earlier, is particularly informative in this regard. In Atchley et al.'s last experiment, the onset of the target was marked by a luminance transient but was not characterized by the onset of a new object. The participants were, therefore, presumably set for luminance transients, but not for the appearance of a new object. In this case, no (contingent) capture ensued-contrary to what one would have expected if capture in the other experiments in Atchley et al.'s study had been the result of an attentional set for luminance transients. Contingent capture was observed only when the luminance change in the cue was made appreciably larger (Atchley et al., 2000, Experiment 4b). This increase in the magnitude of the luminance change in the cue, however, was accompanied by an equal increase in the magnitude of the luminance change in the target. If one assumes that sufficiently large feature changes are treated as tantamount to the appearance of a new object, it is possible that both the cue and the probe were now being treated as new perceptual objects by the visual system. As in the studies by Posner, Lambert, and others, the cue may have captured attention because the participants were set for new objects and the cue itself was treated like a new object.

Franconeri and Simons's (2003), Enns et al.'s (2001), and Yantis's (1993a; Hillstrom \& Yantis, 1994; Yantis \& Hillstrom, 1994) invocations of ecology raise a larger issue. Some of the experiments described in the preceding sections involved the transformation of existing objects. Franconeri and Simons's $(2001,2003)$ stimuli expanded in size or changed color abruptly; Theeuwes's (1990) stimuli changed shape; Enns et al.'s stimuli underwent a simultaneous polarity and contrast change. All of these transformations formally represented a change to an old object. However, it may very well have been that they were treated by the visual system as constituting the emergence of a new object. ${ }^{18}$ Yantis and Gibson's (1994) results suggest that whether something is treated as a new perceptual object or as a second instance of an already established object is a question of spatiotemporal object continuity. It is conceivable that those changes that appeared to capture attention in the above experiments represented ecologically implausible transformations (transformations that violated the contingencies of the natural world $)^{19}$ and, therefore, disrupted the spatiotemporal continuity of the changed objects. In this case, the changes in Franconeri and Simons's (2001, 2003), Theeuwes's (1990), and Enns et al.'s experiments may have been considered onsets of new perceptual objects, which in turn captured attention, as has been proposed by Yantis (1993a). What supports this interpretation is the fact that Enns et al. obtained capture only with an ecologically unlikely combination of contrast and polarity change, whereas polarity change by itself did not capture attention.

In a recent study, Rauschenberger (2003) examined the possibility more directly that changes to existing objects may (under some conditions) be treated as constituting the emergence of a new object. In this study, new object targets were paired with a variety of uninformative cues. Three different types of cues were used: an onset cue, a luminance change cue, and a luminance singleton cue (see Figure 7). In the onset cue condition, a single set of four dots appeared, surrounding one of the display locations, just as in Folk et al.'s (1992) onset cue condition. In the luminance change condition, all display 
New object

cue

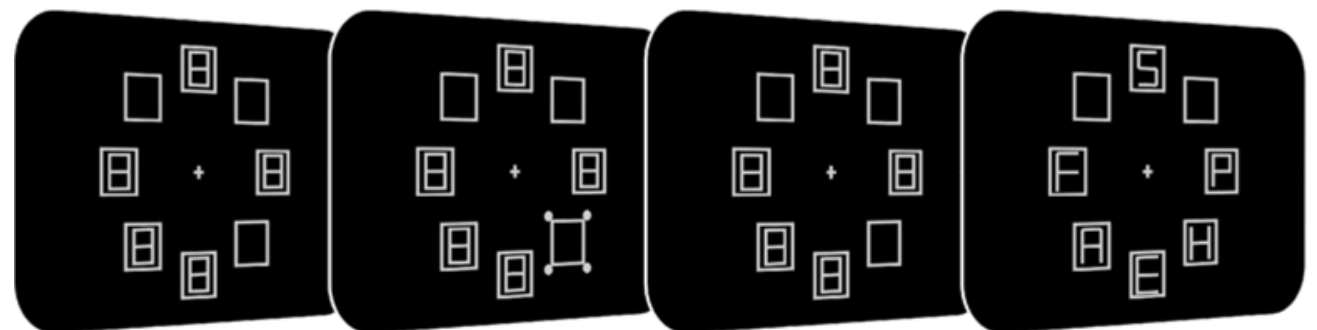

Luminance change cue

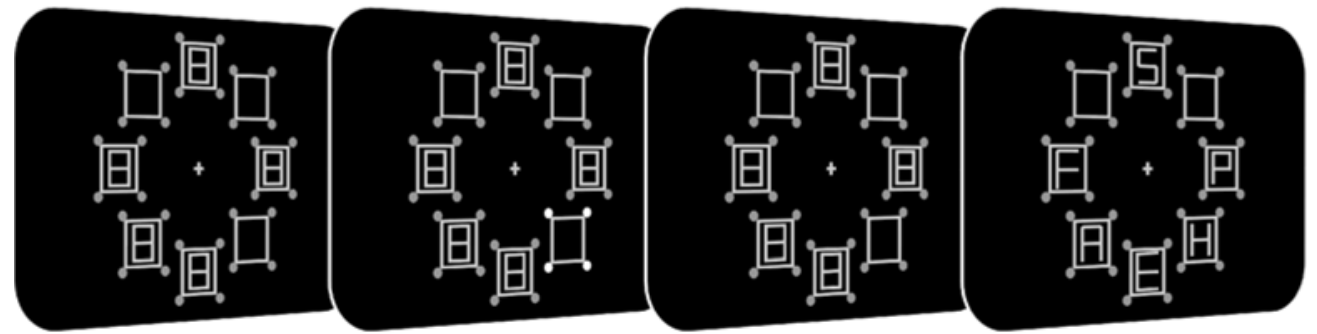

\section{Luminance singleton cue}

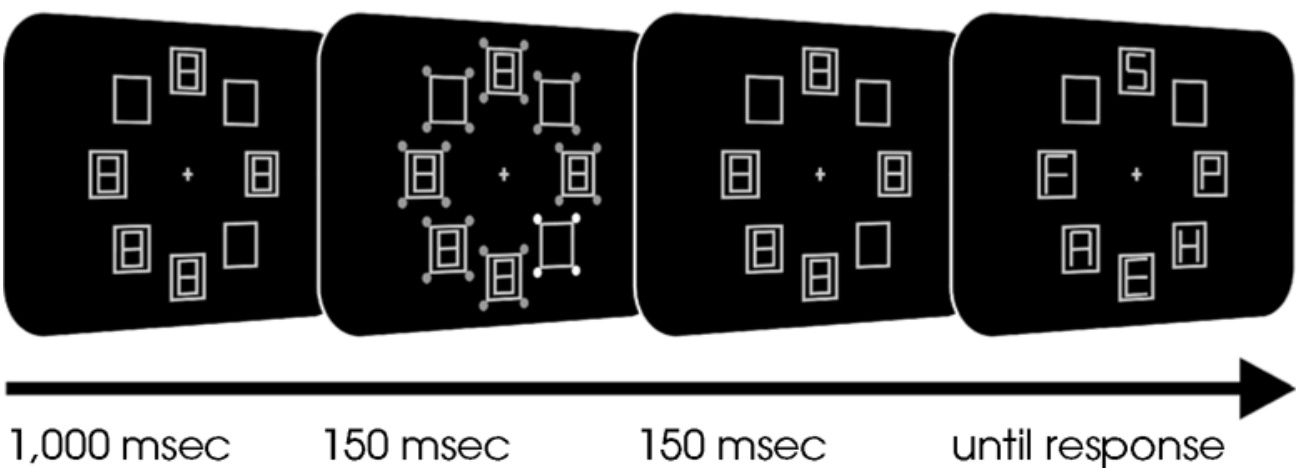

Figure 7. Example of the displays used by Rauschenberger (2003). The new-object cue appeared abruptly in a previously blank location. In the luminance change condition, this location was already occupied for $1,000 \mathrm{msec}$ by a set of small disks, which abruptly changed in luminance in the cue display. In the luminance singleton condition, there were abrupt onsets at all of the display locations. However, one set of onsetting disks distinguished itself from the others by virtue of its greater luminance. The luminance contrast between the old disks and the brighter disks in the luminance change condition was the same as the contrast between the dimmer and the brighter disks in the luminance singleton condition. The participants were set to search for the new object, which was always the target. From "When Something Old Becomes Something New: Spatiotemporal Object Continuity and Attentional Capture,” by R. Rauschenberger, 2003, Journal of Experimental Psychology: Human Perception \& Performance, 29, p. 602. Copyright 2003 by the American Psychological Association. Reprinted with permission.

locations were surrounded by sets of four dim dots (cue placeholders; see Atchley et al., 2000), and one set of four dots transiently increased in luminance. In the luminance singleton cue condition, the cue placeholders were omitted, so that only the cue display with one set of bright dots among dimmer dots appeared abruptly. The purpose of this condition was to rule out the possibility that any contingent capture produced by the luminance change condition was due to the salience of the bright cue against its background of dimmer dots. The three cue conditions were factorially combined with three different magnitudes of luminance contrast. 
Rauschenberger (2003) found that onset cues captured attention at both the smallest and the largest luminance contrasts. The luminance change cues, by contrast, produced an effect only at the largest luminance change magnitude, and not with any smaller luminance changes. The luminance singleton cue did not yield any evidence of contingent capture even at the largest luminance contrast. These results demonstrate that sufficiently large luminance changes to existing objects may capture attention when participants are set for new objects. They suggest that some instances of featural change may be interpreted as constituting the emergence of a new object. What precipitates the opening of a new object file, in this case, is the disruption of the spatiotemporal continuity of the object undergoing the featural change.

Rauschenberger investigated the effects of relatively large luminance changes on the spatiotemporal continuity of objects within the context of a Ternus display (Pantle \& Picciano, 1976; Pikler, 1917; Ternus, 1926; Wertheimer, 1912). The Ternus display is an instance of an ambiguous apparent motion display that gives rise to one of two alternative percepts: At short temporal intervals between successive frames, observers mainly report seeing a peripheral dot leaping back and forth around a stationary center dot (element motion); at longer intervals, a pair of dots is seen moving in tandem in a left-right motion (group motion; see Pantle \& Picciano, 1976). The two different percepts have been explained in terms of temporal grouping of the first instance of the central dot with its second occurrence (see He \& Ooi, 1999; Kramer \& Yantis, 1997; Yantis, 1995). At short temporal intervals, the central dot is seen as continuous across the temporal gap between frames; because it is perceived as stationary, the only remaining interpretation for the other dot is to be moving back and forth across this stationary dot. The persistence of the central dot across frames appears to be mediated not by visual persistence (see Kramer \& Rudd, 1999), but by the spatiotemporal continuity of the object representation for the central dot (Yantis, 1995; Yantis \& Gibson, 1994). If the luminance change in the experiment described earlier caused a disruption of the spatiotemporal continuity of the change cue, a change of equal magnitude should disrupt the spatiotemporal continuity of the central dot in the Ternus display as well, giving rise to a greater probability of observing group motion. This is precisely the result that Rauschenberger (2003) obtained.

\section{Summary}

Although further research is clearly necessary, the results of experiments with dynamic cues other than new objects are consistent with an interpretation according to which certain dynamic cues are interpreted as new objects. This very possibility should invite caution when the results from capture experiments using change cues are interpreted. At the same time, it exposes a certain weakness in the new object concept: If any cue can be reinterpreted as a new-object cue, the proposal that new objects capture attention runs the danger of becoming nonfalsifiable. Studies like Rauschenberger's (2003) can potentially provide a solution to this problem by testing the bounding conditions for new-object status.

\section{CONCLUDING REMARKS}

In the preceding review, the potential of various types of cues to capture attention was examined. Several basic themes have emerged from this review, the most important of which are summed up in the following sections. In part, these themes are empirical and, in part, methodological/ theoretical. One of the central arguments of this article is that these two sets of themes are inextricably linked: Whatever empirical evidence has been brought to bear on the ability of a given type of cue to capture attention can be discussed only relative to the particular methods that have been employed to produce this evidence. The present review represents an attempt to find a common theoretical denominator for the wealth of studies that have examined attentional capture-each possessing its own set of assumptions and operationalization of capture.

\section{Empirical and Methodological/Theoretical Themes}

\section{Static Versus Dynamic Cues}

When the available empirical evidence is examined within such a methodological framework, the following picture emerges. There appears to be a general divide between static and dynamic singletons. Reports that static cues capture attention have come largely from paradigms in which capture is confounded with an acute awareness of the presence of the static cue. Although static cues do appear to impress themselves on the observer's consciousness, there is little evidence that they capture spatial attention (see, however, Theeuwes \& Godijn, 2002). Perhaps the very fact that static cues can so easily be "read" off a display makes it unnecessary for them to capture attention. The contrast between the cue and its context is, after all, static. The cue remains available for inspection if necessary, and its singleton status does not change over time.

By contrast, dynamic cues are distinguished from their surround only by virtue of their distinct histories. ${ }^{20}$ Once the cue has appeared or changed, it no longer distinguishes itself from its context by any static features. If attention is not directed to the cue at the time of its appearance (or change), the opportunity to access the item rapidly is relinquished. In this case, the item needs to be searched effortfully, along with all of the other items in the display. Search slopes for trials in which attention was not captured successfully in Enns et al.'s (2001) study illustrate how inefficient selection can be in this case, as compared with trials in which attention was captured successfully (see Figure 5). Camouflage would be quite trivial if dynamic stimuli did not elicit an automatic shift of attention-with rather dangerous results for potential prey. 
Visual marking. The only recourse, in this case, would be a strategy that would allow the existing objects in a scene to be inhibited top-down, so that new items, even though they may not capture attention or stand out perceptually, may be searched relatively efficiently. Watson and Humphreys (1997) have reported results from visual search consistent with precisely such a strategy. They refer to this strategy as visual marking. In visual marking, search items are presented in two temporally separated batches. The first of the two sets of items, the preview display, never contains the target, and it is, therefore, beneficial to limit search to the second set of items. Watson and Humphreys (1997) showed that participants are indeed capable of limiting their search to the second set of items when it is beneficial to do so (cf. Watson \& Humphreys, 2000). They have argued that visual marking does not occur because of attentional capture by the second, abruptly onsetting display (see, however, Donk $\&$ Theeuwes, 2001). It appears instead to be a deliberate, flexible, and attention-demanding process of inhibiting the old items (see Olivers \& Humphreys, 2002; Watson $\&$ Humphreys, 2000). Theeuwes, Kramer, and Atchley (1998) furthermore showed that it does not depend on the physical distinctness of the two sets of items (see also Watson, 2001). Given these characteristics, visual marking would provide a good "backup" mechanism in case neither stimulus salience nor attentional capture succeeded in providing the opportunity for rapid inspection of a behaviorally highly pertinent object.

\section{Allo- Versus Auto-Cues}

What emerges from the preceding review is not only an empirical, potentially theoretically significant distinction between static and dynamic cues, with the latter capturing attention and the former affording perceptual salience, but also a theoretically meaningful distinction between two general classes of capture paradigms: alloand auto-cuing paradigms. As was suggested in the introduction, the two may be characterized by different time courses, reflecting the different underlying mechanisms associated with each paradigm. These differences in time course further interact with the type of cue (static vs. dynamic): Whereas feature cues have a slow rise time in allo-cue paradigms, onset cues show their effect early on. In auto-cue paradigms, both static and dynamic cues evidence a fast rise time. The lesson for research on attentional capture is that these differences should be considered in selecting the proper type of paradigm for a particular cue.

Object-based attention. The differences in time course between allo- and auto-cues had been attributed to the fact that, in the former, attention needs to be relayed from the cue to the probe via the shared spatial location of the two objects, whereas auto-cues attract attention to themselves without mediation. This mediation of the attentional effect via the shared identity of the cue and the probe creates a natural connection between the cuing literature and the literature on object-based atten- tion. Indeed, the distinction between the location-relayed allo-cue and the object-mediated auto-cue may have implications for the study of object-based attention. Typically, in the paradigms in which object-based attention has been studied (e.g., Egly, Driver, \& Rafal, 1994), the cuing of a given object has been accomplished by the brightening of one side of the object, and the probe, in turn, has represented a further modification of the same object (for within-object cues).

Selection, in this paradigm, can be broken down into two components: a spatial and an object-based component. If only the object-based component is considered, the paradigm reveals itself as an auto-cue paradigm. At first glance, it may seem inconsistent to refer to Egly et al.'s (1994) paradigm as an auto-cue paradigm, because the cue and the probe are ostensibly separated in space and time. However, the emphasis should be on the spatiotemporal continuity of the object mediating the attentional effect: Both the cue and the probe represent modifications of the same object, and the very fact that an object-based effect exists, by definition, makes the paradigm an autocue paradigm. In accordance with the temporal characteristics of auto-cues, Lamy and Egeth (2002) reported the object-based component to be SOA independent and present as early as $100 \mathrm{msec}$ after the onset of the cue. If only the spatial component is considered, the very same paradigm can be reinterpreted as an allo-cue paradigm. Here, the emphasis should be on the spatiotemporal separation of the cue and the probe, because mediation by the cued object is factored out. In contrast to the SOA independence of the object-based component, and consistent with the time course of allo-cues, Lamy and Egeth found that the spatial component did not reach its full potential at $100 \mathrm{msec}$ but evolved as a function of SOA.

\section{Ambiguities in Capture}

\section{Guidance and Prioritization Versus Capture}

The third theme that characterizes the preceding review concerns the mode of attentional prioritization. Regardless of the paradigm that is used to investigate attentional capture, capture results are often ambiguous. On the one hand, when a performance benefit is observed or when search slopes are flat, these findings may be due to (1) attention's genuinely being captured involuntarily, (2) attention's being guided efficiently, with the cue serving as a landmark, or (3) the cue/probe's being placed at the top of a processing queue without otherwise eliciting an automatic shift of attention. On the other hand, when a performance cost is observed or when search slopes are moderately steep, these results may be due to (1) the genuine capture of attention by a distractor, (2) the misguidance of attention, (3) filtering costs, or (4) the failure of attentional capture on a subset of trials. In any case, the pattern of results does not unambiguously specify the underlying mechanism. Future research in this area will need to place an equal emphasis on the analysis and disambiguation of data as the development and proper selection of paradigms. 


\section{New Object Versus Changed Object}

The present article identified a second, different type of ambiguity - the fourth and final theme that can be distilled from the preceding review. It had been concluded that, apart from new objects, other types of dynamic cues capture attention as well (e.g., Franconeri \& Simons, 2001, 2003; Lambert \& Hockey, 1991). However, following the results of Rauschenberger (2003), it remains unclear whether capture, in these cases, is mediated by the interpretation of the dynamic cues as new objects. Given the importance of the new-object concept in the attentional capture literature, future efforts in this area should, perhaps, be directed at providing a tighter definition for this concept. In particular, delineating the concept of an altered existing object from that of new perceptual objects (e.g., Rauschenberger, 2003) and empirically deriving boundaries for what constitutes an ecologically plausible transformation may prove helpful in the currently somewhat circular definition of the new-object concept.

\section{REFERENCES}

Atchley, P., Kramer, A. F., \& Hillstrom, A. P. (2000). Contingent capture for onsets and offsets: Attentional set for object transients. Journal of Experimental Psychology: Human Perception \& Performance, 26, 594-606.

BACON, W. F., \& EGETH, H. E. (1991). Local processes in preattentive feature detection. Journal of Experimental Psychology: Human Perception \& Performance, 17, 77-90.

BACON, W. F., \& EGETH, H. E. (1994). Overriding stimulus-driven attentional capture. Perception \& Psychophysics, 55, 485-496.

Bichot, N. P., CAVE, K. R., \& PASHler, H. (1999). Visual selection mediated by location: Feature-based selection of noncontiguous locations. Perception \& Psychophysics, 61, 403-423.

Braun, J. (1998). Vision and attention: The role of training. Nature, 393, 424-425.

Braun, J., \& Sagi, D. (1990). Vision outside the focus of attention. Perception \& Psychophysics, 48, 45-58.

Braun, J., \& SAGI, D. (1991). Texture-based tasks are little affected by second tasks requiring peripheral or central attentive fixation. Perception, 20, 483-500.

Bravo, M. J., \& NAKAYAMA, K. (1992). The role of attention in different visual-search tasks. Perception \& Psychophysics, 51, 465-472.

BreitMeyer, B., \& JulesZ, B. (1975). The role of on and off transients in determining the psychophysical spatial frequency response. Vision Research, 15, 411-415.

CARlson, R. L, \& Shomstein, S. (2001). Disambiguating strategic effects in visual search [Abstract]. Journal of Vision, 1, 119.

CAVE, K. R., \& WOLFE, J. M. (1990). Modeling the role of parallel processing in visual search. Cognitive Psychology, 22, 225-271.

CAVE, K. R., \& Zimmerman, J. M. (1997). Flexibility in spatial attention before and after practice. Psychological Science, 8, 399-403.

Ce Peda, N. J., CAVE, K. R., Bichot, N. P., \& KiM, M.-S. (1998). Spatial selection via feature-driven inhibition of distractor locations. Perception \& Psychophysics, 60, 727-746.

Chastain, G., \& Cheal, M. (1998). Automatic versus directed attention with single-element and multiple-element precues. Visual Cognition, 5, 339-364.

Chastain, G., \& Cheal, M. (1999a). Time course of attention effects with abrupt-onset and offset single- and multiple-element precues. American Journal of Psychology, 112, 411-436.

Chastain, G., \& Cheal, M. (1999b, November). Validity effects with offset and onset distractors and targets. Poster presented at the 40th Annual Meeting of the Psychonomic Society, Los Angeles.

Cheal, M., \& Chastain, G. (1998). Attention effects of moving and stationary single-element and multiple-element precues: Limits of automaticity. Perception \& Psychophysics, 60, 873-887.

Cole, G., Gellatly,A., \& Blurton, A. (2001). Effect of object onset on the distribution of visual attention. Journal of Experimental Psychology: Human Perception \& Performance, 27, 1356-1368.

Di Lollo, V., Kawahara, J., Zuvic, S. M., \& Visser, T. A. (2001). The preattentive emperor has no clothes: A dynamic redressing. Journal of Experimental Psychology: General, 130, 479-492.

DONK, M., \& THEeUWES, J. (2001). Visual marking beside the mark: Prioritizing selection by abrupt onsets. Perception \& Psychophysics, 63, 891-900.

DUNCAN, J. (1984). Selective attention and the organization of visual information. Journal of Experimental Psychology: General, 113, 501517.

DunCAN, J., \& HumphreYs, G. W. (1989). Visual search and stimulus similarity. Psychological Review, 96, 433-458.

DunCAN, J., \& Humphreys, G. W. (1992). Beyond the search surface: Visual search and attentional engagement. Journal of Experimental Psychology: Human Perception \& Performance, 18, 578-588.

EGLY, R., DRIVER, J., \& RAFAL, R. (1994). Shifting visual attention between objects and locations: Evidence from normal and parietal lesion subjects. Journal of Experimental Psychology: General, 123, 161-177.

Enns, J. T., Austen, E. L., Di Lollo, V., Rauschenberger, R., \& YANTIS, S. (2001). New objects dominate luminance transients in setting attentional priority. Journal of Experimental Psychology: Human Perception \& Performance, 27, 1287-1302.

ERIKSEN, C. W., \& Hoffman, J. E. (1973). The extent of processing of noise elements during selective encoding from visual displays. Perception \& Psychophysics, 14, 155-160.

FolK, C. L., \& ANNETT, S. (1994). Do locally defined feature discontinuities capture attention? Perception \& Psychophysics, 56, 277287.

FolK, C. L., \& EGETH, H. E. (1989). Does the identification of simple features require serial processing? Journal of Experimental Psychology: Human Perception \& Performance, 15, 97-110.

Folk, C. L., Leber, A. B., \& Egeth, H. E. (2002). Made you blink! Contingent attentional capture produces a spatial blink. Perception \& Psychophysics, 64, 741-753.

Folk, C. L., \& Remington, R. [W.] (1996). When knowledge does not help: Limitations on the flexibility of attentional control. In A. F. Kramer, M. G. H. Coles, \& G. D. Logan (Eds.), Converging operations in the study of selective attention (pp. 271-295). Washington, DC: American Psychological Association.

FOLK, C. L., \& REMINGTON, R. [W.] (1998). Selectivity in distraction by irrelevant featural singletons: Evidence for two forms of attentional capture. Journal of Experimental Psychology: Human Perception \& Performance, 24, 847-858.

Folk, C. L., \& Remington, R. [W.] (1999). Can new objects override attentional control settings? Perception \& Psychophysics, 61, 727739

Folk, C. L., Remington, R. W., \& Johnston, J. C. (1992). Involuntary covert orienting is contingent on attentional control settings. Journal of Experimental Psychology: Human Perception \& Performance, 18, 1030-1044.

Folk, C. L., Remington, R. W., \& Johnston, J. C. (1993). Contingent attentional capture: A reply to Yantis (1993). Journal of Experimental Psychology: Human Perception \& Performance, 19, 682-685.

Folk, C. L., Remington, R. W., \& Wright, J. H. (1994). The structure of attentional control: Contingent attentional capture by apparent motion, abrupt onset, and color. Journal of Experimental Psychology: Human Perception \& Performance, 20, 317-329.

FrANCONERI, S. L., \& SimONS, D. J. (2001, May). Abruptonsets are not unique in capturing attention. Poster session presented at the annual meeting of the Vision Sciences Society, Sarasota, FL.

FrANCONERI, S. L., \& Simons, D. J. (2003). Moving and looming stimuli capture attention. Perception \& Psychophysics, 65, 999-1010.

Gellatly, A., \& Cole, G. (2000). Accuracy of target detection in newobject and old-object displays. Journal of Experimental Psychology: Human Perception \& Performance, 26, 889-899. 
Gellatly, A., Cole, G., \& Blurton, A. (1999). Do equiluminant object onsets capture visual attention? Journal of Experimental Psychology: Human Perception \& Performance, 25, 1609-1624.

GHirardelli, T. G., \& EGETH, H. E. (1998). Goal-directed and stimulusdriven attention in cross-dimensional texture segregation. Perception \& Psychophysics, 60, 826-838.

GiBSON, B. S. (1996a). The masking account of attentional capture: A reply to Yantis and Jonides (1996). Journal of Experimental Psychology: Human Perception \& Performance, 22, 1514-1520.

GiBson, B. S. (1996b). Visual quality and attentional capture: A challenge to the special role of abrupt onsets. Journal of Experimental Psychology: Human Perception \& Performance, 22, 1496-1504.

GiBson, B. S. (1999, November). A closer look at contingent capture. Paper presented at the 40th Annual Meeting of the Psychonomic Society, Los Angeles.

Gibson, B. S., \& AMELio, J. (2000). Inhibition of return and attentional control settings. Perception \& Psychophysics, 62, 496-504.

Gibson, B. S., \& Jiang, Y. (1998). Surprise! An unexpected color singleton does not capture attention in visual search. Psychological Science, 9, 176-182.

Gibson, B. S., \& Kelsey, E. M. (1998). Stimulus-driven attentional capture is contingent on attentional set for displaywide visual features. Journal of Experimental Psychology: Human Perception \& Performance, 24, 699-706.

Grandison, T., Vaughan, B., \& Yantis, S. (1997, May). Context affects attentional capture by object onsets. Poster session presented at the annual meeting of the Association for Research in Vision and Ophthalmology, Fort Lauderdale, FL.

HALPERN, D. F. (1987). The functional equivalence of objective and illusory brightness enhancement. In S. J. Petri \& G. E. Meyer (Eds.), The perception of illusory contours (pp. 171-175). New York: SpringerVerlag.

Hassenstein, B., \& Hustert, R. (1999). Hiding responses of locusts to approaching objects. Journal of Experimental Biology, 202, 1701 1710.

HE, Z. J., \& OOI, T. L. (1999). Perceptual organization of apparent motion in the Ternus display. Perception, 28, 877-892.

Hillstrom, A. P., \& YANTiS, S. (1994). Visual motion and attentional capture. Perception \& Psychophysics, 55, 399-411.

Horstmann, G. (2002). Evidence for attentional capture by a surprising color singleton in visual search. Psychological Science, 6, 499-505.

Irwin, D. E., Colcombe, A. M., Kramer, A. F., \& HAhn, S. (2000). Attentional and oculomotor capture by onset, luminance and color singletons. Vision Research, 40, 1443-1458.

Johnson, J. D., Hutchinson, K. A., \& NeIll, W. T. (2001). Attentional capture by irrelevant color singletons. Journal of Experimental Psychology: Human Perception \& Performance, 27, 841-847.

JONIDES, J. (1981). Voluntary vs. automatic control over the mind's eye's movement. In J. [B.] Long \& A. [D.] Baddeley (Eds.), Attention and performance IX (pp. 187-203). Hillsdale, NJ: Erlbaum.

JONIDES, J., \& MACK, R. (1984). On the cost and benefit of cost and benefit. Psychological Bulletin, 96, 29-44.

JONIDES, J., \& YANTIS, S. (1988). Uniqueness of abrupt visual onset in capturing attention. Perception \& Psychophysics, 43, 346-354.

Jose PH, J. S., Chun, M. M., \& NAKAyAma, K. (1997). Attentional requirements in a "preattentive" feature search task. Nature, 387, 805807.

JOSEPH, J. S., \& OPTICAN, L. M. (1996). Involuntary attentional shifts due to orientation differences. Perception \& Psychophysics, 58, 651665.

Juola, J. F., Koshino, H., \& WARner, C. B. (1995). Tradeoffs between attentional effects of spatial cues and abrupt onsets. Perception \& Psychophysics, 57, 333-342.

Kahneman, D., \& HeniK, A. (1981). Perceptual organization and attention. In M. Kubovy \& J. R. Pomerantz (Eds.), Perceptual organization (pp. 181-211). Hillsdale, NJ: Erlbaum.

Kahneman, D., \& Treisman, A. M. (1984). Changing views of attention and automaticity. In R. Parasuraman \& D. A. Davies (Eds.), Varieties of attention (pp. 29-61). San Diego: Academic Press.

Kahneman, D., Treisman, A. M., \& Gibbs, B. J. (1992). The review- ing of object files: Object-specific integration of information. Cognitive Psychology, 24, 175-219.

KIM, M. S., \& CAVE, K. R. (1995). Spatial attention in visual search for features and feature conjunctions. Psychological Science, 6, 376-380.

King, S. M., Dy Keman, C., Redgrave, P., \& DeAn, P. (1992). Use of a distracting task to obtain defensive head movements to looming visual stimuli by human adults in a laboratory setting. Perception, 21, 245-259.

Koch, C., \& Ullman, S. (1985). Shifts in selective attention: Toward the underlying neural circuitry. Human Neurobiology, 4, 219-227.

Koshino, H., Warner, C. B., \& JuOla, J. F. (1992). Relative effectiveness of central, peripheral, and abrupt-onset cues in visual attention. Quarterly Journal of Experimental Psychology, 45A, 609-631.

KRAMER, P., \& RUDD, M. (1999). Visible persistence and form correspondence in Ternus apparent motion. Perception \& Psychophysics, 61, 952-962.

KrAmeR, P., \& YANTIS, S. (1997). Perceptual grouping in space and time: Evidence from the Ternus display. Perception \& Psychophysics, 59, 87-99.

KrumhansL, C. L. (1982). Abrupt changes in visual stimulation enhance processing of form and location information. Perception \& Psychophysics, 32, 511-523.

LAMBERT, A., \& Hockey, R. (1991). Peripheral visual changes and spatial attention. Acta Psychologica, 76, 149-163.

LAmbert, A., SPEnCER, E., \& Mohindra, N. (1987). Automaticity and the capture of attention by a peripheral display change. Current Psychological Research \& Reviews, 6, 136-147.

LAMY, D., \& EGETH, H. (2002). Object-based selection: The role of attentional shifts. Perception \& Psychophysics, 64, 52-66.

LAMY, D., \& TSAL, Y. (1999). A salient distractor does not disrupt conjunction search. Psychonomic Bulletin \& Review, 6, 93-98.

LENNIE, P. (1980). Parallel visual pathways: A review. Vision Research, 20, $562-594$.

MARTIN-EMERSON, R., \& KRAMER, A. F. (1997). Offset transients modulate attentional capture by sudden onsets. Perception \& Psychophysics, 59, 739-751.

MAYLOR, E. A. (1985). Facilitatory and inhibitory components of orienting in visual space. In M. I. Posner \& O. S. M. Martin (Eds.), Attention and Performance XI (pp. 189-204). Hillsdale, NJ: Erlbaum.

Mille R, J. (1989). The control of attention by abrupt visual onsets and offsets. Perception \& Psychophysics, 45, 567-571.

MounTs, J. R. W. (2000). Evidence for suppressive mechanisms in attentional selection: Feature singletons produce inhibitory surrounds. Perception \& Psychophysics, 62, 969-983.

Mounts, J. R. W., \& Melara, R. D. (1999). Attentional selection of objects or features: Evidence from a modified search task. Perception \& Psychophysics, 61, 322-341.

MülleR, H. J., \& RABBitT, P. M. A. (1989). Reflexive and voluntary orienting of visual attention: Time course of activation and resistance to interruption. Journal of Experimental Psychology: Human Perception \& Performance, 15, 315-330.

NAKAYAMA, K. (1990). The iconic bottleneck and the tenuous link between early visual processing and perception. In C. Blakemore (Ed.), Vision: Coding and efficiency (pp. 411-422). New York: Cambridge University Press.

NAKAYAMA, K. (1999, November). Object perception and memory in visual search. Paper presented at the annual Workshop on Object Perception and Memory (OPAM), Los Angeles.

NAKAYAMA, K., \& JOSE PH, J. S. (1998). Attention, pattern recognition, and pop-out in visual search. In R. Parasuraman (Ed.), The attentive brain (pp. 279-298). Cambridge, MA: MIT Press.

NAKAYAMA, K., \& MACKEBEN, M. (1989). Sustained and transient components of focal visual attention. Vision Research, 29, 1631-1647.

NANE Z, J. E. (1988). Perception of impending collision in 3- to 6-weekold infants. Infant Behavior \& Development, 11, 447-463.

NANEZ, J. E., \& YonAS, A. (1995). Effects of luminance and texture motion on infant defensive reactions to optical collision. Infant Behavior \& Development, 17, 165-174.

Olivers, C. N. L., \& Humphreys, G. W. (2002). When visual marking meets the attentional blink: More evidence for top-down, limited- 
capacity inhibition. Journal of Experimental Psychology: Human Perception \& Performance, 28, 22-42.

OONK, H. M., \& ABRAMs, R. A. (1998). New perceptual objects that capture attention produce inhibition of return. Psychonomic Bulletin \& Review, 5, 510-515.

Pantle, A. J., \& Picciano, L. (1976). A multistable movement display: Evidence for two separate motion systems in human vision. Science, 193, 500-502.

PASHLER, H. (1988). Cross-dimensional interaction and texture segregation. Perception \& Psychophysics, 43, 307-318.

PhILlips, W. A., \& SingeR, W. (1974). Function and interaction of on and off transients in vision: 1. Psychophysics. Experimental Brain Research, 19, 493-506.

PIKLE R, J. (1917). Sinnesphysiologische Untersuchungen. Leipzig: Barth.

Posner, M. I. (1980). Orienting of attention. Quarterly Journal of Experimental Psychology, 32, 3-25.

Posner, M. I., \& Cohen, Y. (1984). Components of visual orienting. In H. Bouma \& D. G. Bouwhuis (Eds.), Attention and performance X: Control of language processes (pp. 531-556). Hillsdale, NJ: Erlbaum.

Posner, M. I., Cohen, Y., \& RAFAL, R. D. (1982). Neural systems control of spatial orienting. Philosophical Transactions of the Royal Society of London: Series B, 298, 87-198.

Pratt, J., Sekuler, A. B., \& MCAuliffe, J. (2001). The role of attentional set on attentional cuing and inhibition of return. Visual Cognition, 8, 22-46.

Proulx, M. J. (2002). No contingencies: Attentional prioritization by big or bright singletons. Unpublished master's thesis, Johns Hopkins University.

RAUSCHENBERGER,R. (2003). When something old becomes something new: Spatiotemporal object continuity and attentional capture. Journal of Experimental Psychology: Human Perception \& Performance, 29, 600-615.

RAUSChEnberger, R., \& YAntis, S. (2001). Attentional capture by globally defined objects. Perception \& Psychophysics, 63, 12501261.

Remington, R. W., Johnston, J. C., \& YAntis, S. (1992). Involuntary attentional capture by abrupt onsets. Perception \& Psychophysics, 51, 279-290.

Schiff, W., Caviness, J. A., \& Gibson, J. J. (1962). Persistent fear responses in rhesus monkeys to the optical stimulus of "looming." Science, 136, 982-983.

Scholl, B. J., Pylyshyn, Z. W., \& Feldman, J. (2001). What is a visual object? Evidence from target merging in multiple-object tracking. Cognition, 80, 159-177.

SimONS, D. J. (2000). Attentional capture and inattentional blindness. Trends in Cognitive Sciences, 4, 147-155.

Singer, W., \& PhILlips, W. A. (1974). Function and interaction of on and off transients in vision: 2. Neurophysiology. Experimental Brain Research, 19, 507-521.

Stevens, S. S., \& Galanter, E. H. (1957). Ratio scales and category scales on a dozen perceptual continua. Journal of Experimental Psychology, 54, 377-411.

TERNUS, J. (1926). Experimentelle Untersuchungen über phänomenale Identität. Psychologische Forschung, 7, 81-136.

TheEuwes, J. (1990). Perceptual selectivity is task dependent: Evidence from selective search. Acta Psychologica, 74, 81-99.

Theeuwes, J. (1991a). Cross-dimensional perceptual selectivity. Perception \& Psychophysics, 50, 184-193.

THEEUWES, J. (1991b). Exogenous and endogenous control of attention: The effect of visual onsets and offsets. Perception \& Psychophysics, 49, 83-90.

Theeuwes, J. (1992). Perceptual selectivity for color and form. Perception \& Psychophysics, 51, 599-606.

THEEUWES, J. (1994). Stimulus-driven capture and attentional set: Selective search for color and visual abrupt onsets. Journal of Experimental Psychology: Human Perception \& Performance, 20, 799-806.

Theeuwes, J. (1995a). Abrupt luminance change pops out; abrupt color change does not. Perception \& Psychophysics, 57, 637-644.

THEEUWES, J. (1995b). Temporal and spatial characteristics of preattentive and attentive processing. Visual Cognition, 2, 221-233.
TheEUWES, J. (1996). Perceptual selectivity for color and form: On the nature of the interference effect. In A. F. Kramer, M. G. H. Coles, \& G. D. Logan (Eds.), Converging operations in the study of visual selective attention (pp. 297-314). Washington, DC: American Psychological Association.

TheeuWes, J., ATChley, P., \& KrAmer, A. F. (2000). On the time course of top-down and bottom-up control of visual attention. In S. Monsell \& J. Driver (Eds.), Attention and performance XVIII: Control of cognitive processes (pp. 105-124). Cambridge, MA: MIT Press.

THEeUWES, J., \& BURGER, R. (1998). Attentional control during visual search: The effect of irrelevant singletons. Journal of Experimental Psychology: Human Perception \& Performance, 24, 1342-1353.

Theeuwes, J., \& Godin, R. (2002). Irrelevant singletons capture attention: Evidence from inhibition of return. Perception \& Psychophysics, 64, 764-770.

Theeuwes, J., Kramer, A. F., \& Atchley, P. (1998). Visual marking of old objects. Psychonomic Bulletin \& Review, 5, 130-134.

Theeuwes, J., Kramer, A. F., \& Atchley, P. (1999). Attentional effects of preattentive vision: Spatial precues affect the detection of simple features. Journal of Experimental Psychology: Human Perception \& Performance, 25, 341-347.

Theeuwes, J., Kramer, A. F., \& ATChley, P. (2001). Spatial attention in early vision. Acta Psychologica, 108, 1-20.

Thomas, S. J., \& LUCK, S. J. (2000). Multiple pathways to the automatic capture of attention. Unpublished manuscript.

TODD, J. T., \& VAN GELDER, P. (1979). Implications of a transientsustained dichotomy for the measurement of human performance. Journal of Experimental Psychology: Human Perception \& Performance, 5, 625-638.

TodD, S., \& Kramer, A. F. (1994). Attentional misguidance in visual search. Perception \& Psychophysics, 56, 198-210.

Treisman, A. M. (1982). Perceptual grouping and attention in visual search for features and for objects. Journal of Experimental Psychology: Human Perception \& Performance, 8, 194-214.

Treisman, A. M. (1988). Features and objects: The fourteenth Bartlett memorial lecture. Quarterly Journal of Experimental Psychology, 40A, 201-237.

TREISMAN, A. M. (1992). Spreading suppression or feature integration? A reply to Duncan and Humphreys (1992). Journal of Experimental Psychology: Human Perception \& Performance, 18, 589-593.

Treisman, A. M., \& Gelade, G. (1980). A feature-integration theory of attention. Cognitive Psychology, 12, 97-136.

Treisman, A. [M.], Kahneman, D., \& Burkell, J. (1983). Perceptual objects and the cost of filtering. Perception \& Psychophysics, 33, 527-532.

Treisman, A. M., \& Sato, S. (1990). Conjunction search revisited. Journal of Experimental Psychology: Human Perception \& Performance, 16, 459-478.

Turatto, M., \& Galfano, G. (2000). Color, form and luminance capture attention in visual search. Vision Research, 40, 1639-1643.

Turatto, M., \& Galfano, G. (2001). Attentional capture by color without any relevant attentional set. Perception \& Psychophysics, 63, 286-297.

UlLMAN, S. (1984). Visual routines. Cognition, 18, 97-159.

WANG, D. L., KRISTJANSSON, A., \& NAKAYAMA, K. (2001). Efficient visual search without top-down or bottom-up guidance: A putative role for perceptual organization (Cognitive Science Tech. Rep. No. 26). Columbus: Ohio State University, Center for Cognitive Sciences.

WArner, C. B., Juola, J. F., \& Koshino, H. (1990). Voluntary allocation versus automatic capture of visual attention. Perception \& Psychophysics, 48, 243-251.

WATSOn, D. G. (2001). Visual marking in moving displays: Featurebased inhibition is not necessary. Perception \& Psychophysics, 63, 74-84.

Watson, D. G., \& Humphreys, G. W. (1995). Attention capture by contour onsets and offsets: No special role for onsets. Perception \& Psychophysics, 57, 583-597.

Watson, D. G., \& Humphreys, G. W. (1997). Visual marking: Prioritizing selection for new objects by top-down attentional inhibition of old objects. Psychological Review, 104, 90-122. 
WAtson, D. G., \& Humphreys, G. W. (2000). Visual marking: Evidence for inhibition using a probe-dot detection paradigm. Perception \& Psychophysics, 62, 471-481.

Wertheimer, M. (1912). Experimentelle Studien über das Sehen von Bewegung. Zeitschrift für Psychologie, 61, 161-265.

WOLFE, J. M. (1992). "Effortless" texture segmentation and "parallel" visual search are not the same thing. Vision Research, 32, 757-763.

Wolfe, J. M., \& BennetT, S. C. (1996). Preattentive object files: Shapeless bundles of basic features. Vision Research, 37, 25-43.

Wolfe, J. M., CAVE, K. R., \& Franzel, S. L. (1989). Guided search: An alternative to the feature integration model for visual search. Journal of Experimental Psychology: Human Perception \& Performance, 15, 419-433.

Wolfe, J. M., O'NeILl, P., \& BennetT, S. C. (1998). Why are there eccentricity effects in visual search? Visual and attentional hypotheses. Perception \& Psychophysics, 60, 140-156.

YANTIS, S. (1993a). Stimulus-driven attentional capture. Current Directions in Psychological Science, 2, 156-161.

YANTIS, S. (1993b). Stimulus-driven attentional capture and attentional control settings. Journal of Experimental Psychology: Human Perception \& Performance, 19, 676-681.

YANTIS, S. (1995). Perceived continuity of occluded visual objects. Psychological Science, 6, 182-186.

YAntis, S. (1998). Control of visual attention. In H. Pashler (Ed.), Attention (pp. 223-256). Hove, U.K.: Taylor \& Francis.

YANTIS, S. (2000). Goal-directed and stimulus-driven determinants of attentional control. In S. Monsell \& J. Driver (Eds.), Attention and performance XVIII: Control of cognitive processes (pp. 71-208). Cambridge, MA: MIT Press.

YANTIS, S., \& EGETH, H. E. (1999). On the distinction between visual salience and stimulus-driven attentional capture. Journal of Experimental Psychology: Human Perception \& Performance, 25, 661-676.

YANTIS, S., \& GiBSON, B. S. (1994). Object continuity in apparent motion and attention. Canadian Journal of Experimental Psychology, 48, 182-204

YANTIS, S., \& Hillstrom, A. (1994). Stimulus-driven attentional capture: Evidence from equiluminant visual objects. Journal of Experimental Psychology: Human Perception \& Performance, 20, 95-107.

YANTIS, S., \& Johnson, D. N. (1990). Mechanisms of attentional priority. Journal of Experimental Psychology: Human Perception \& Performance, 16, 812-825.

YANTIS, S., \& JONES, E. (1991). Mechanisms of attentional selection: Temporally modulated priority tags. Perception \& Psychophysics, $\mathbf{5 0}$, 166-178.

YANTIS, S., \& JONIDES, J. (1984). Abrupt visual onsets and selective attention: Evidence from visual search. Journal of Experimental Psychology: Human Perception \& Performance, 10, 601-621.

YANTIS, S., \& JONIDES, J. (1990). Abrupt visual onsets and selective attention: Voluntary versus automatic allocation. Journal of Experimental Psychology: Human Perception \& Performance, 16, 121-134.

YANTIS, S., \& JONIDES, J. (1996). Attentional capture by abrupt onsets: New perceptual objects or visual masking? Journal of Experimental Psychology: Human Perception \& Performance, 22, 1505-1513.

\section{NOTES}

1. Whether this privileging of information is accomplished by filtering out irrelevant or unwanted information or by increasing the depth of processing of the attended information remains controversial. However, this question, although of great importance to the study of attention, is not sufficiently relevant for the purposes of the present review to merit a more thorough discussion.

2. Typically, cues are thought of as providing temporal or spatial information about an anticipated event. Here, the term is used more generally to refer to any stimulus that indicates a spatial location and, thereby, has the potential of directing visual attention to that spatial location, regardless of whether the anticipated event will occur in that location or not.

3. For the purposes of this article, the term singleton will be used to denote any stimulus that is unique in some respect within its local context of display elements. This item can be unique either because its features create a feature contrast with its context (feature singleton; Pashler, 1988; e.g., a red item among green items) or because of its singular history (e.g., an item that underwent a color change among items whose color remained constant).

4. Another possibility, suggested by one of the reviewers, is that the auto-cue provides more precise spatial information about the location of the probe. (The cue and the probe are, after all, combined in the same object in this case.) Benefits may, therefore, accrue more quickly with auto-cues than with allo-cues.

5. I would like to thank Jan Theeuwes for suggesting this possibility.

6. The defining attribute is what designates an item as the target; the reported attribute is what underlies participants' responses. For example, if the target is always the red item in the display, the target's defining attribute is the color red. If the participants' task is merely to report the presence or absence of the target, the reported attribute is red as well. If, instead, the target is always either an $H$ or a $U$ and the participants' task is to indicate which of the two it is, the reported attribute is letter identity.

7. Wolfe (1992) has offered some demonstrations that were intended to show that "'Effortless' texture segmentation and 'parallel' visual search are not the same." From these demonstrations, however, it is not apparent that efficient search is not an instance of texture segregation. Figures 5 and 6 in Wolfe are meant to illustrate cases of texture segmentation without parallel search. These displays comprise two levels of hierarchy: They are composed of tilted lines (local items), some of which cluster into a larger patch (global item). Wolfe shows that a local target indeed requires effortful search among its context of local nontarget items but that a global patch comprising these very same items segregates readily from its surrounds. What Wolfe ignored, however, is that the local item that does not permit efficient search also does not support effortless texture segmentation: It does not stand out against its peers of local items. By contrast, the texture that does readily segregate from its background is detected very efficiently. Wolfe made his case by comparing a local target against a global texture. If one does not confuse the different levels of hierarchy in his displays, the claim that these displays demonstrate texture segmentation without parallel search is no longer true.

8. In a series of related experiments, Turatto and Galfano (2000, 2001) observed faster (or more accurate) responses to targets that happened to coincide with feature singletons. However, absolute RTs to these targets were fairly high $(920 \mathrm{msec}$ for Session 1 of Experiment 1$)$, making it unlikely that attention was truly captured in a bottom-up fashion. Furthermore, in the absence of a set size manipulation, it is unclear whether the singleton was reliably investigated first on a large majority of the trials (cf. Enns, Austen, Di Lollo, Rauschenberger, \& Yantis, 2001; Theeuwes, 1990; Yantis \& Jonides, 1984). Given these factors, it is likely that Turatto and Galfano's $(2000,2001)$ results represent a form of what S. Todd and Kramer (1994) have called attentional misguidance.

9. Following Stevens and Galanter (1957), prothetic dimensions are distinguished from metathetic dimensions by possessing directionality. That is, features in a prothetic dimension can be arranged in order of magnitude, whereas features in a metathetic dimension cannot. Although it makes sense to speak of louder and softer or brighter and dimmer, the suggestion that red has "more color" than blue is nonsensical. See Yantis and Egeth (1999) for a discussion.

10. Theeuwes, Kramer, and Atchley (2001) provided evidence that spatial precuing can attenuate the effects of color singleton distractors as well, paralleling the case with onset distractors (Theeuwes, 1991b; Yantis \& Jonides, 1990). They did not observe a complete elimination of the effect of the distractor, however. Because the target and the distractor were both color singletons, it is possible that the participants were engaged in a strategy that induced them to attend indiscriminately to any singleton item (cf. Bacon \& Egeth, 1994). This conclusion is consistent with Folk et al.'s (2002), described further below in the main text.

11. As one of the reviewers pointed out, filtering costs may be subject to top-down modulation, just as shifts of attention are (cf. Bacon \& Egeth, 1994). However, there is, to date, no evidence that filtering costs can be influenced by the participant's search strategy or attentional set.

12. IOR emerges when the time between the cue and the target exceeds $300 \mathrm{msec}$ or so (see Posner \& Cohen, 1984). Although even uninformative exogenous cues normally produce a performance enhancement when the target and the cue happen to coincide spatially, this effect reverses at longer SOAs. It has been argued that IOR represents an in- 
hibition of attention from returning to spatial locations to which it has been previously been summoned exogenously (Maylor, 1985).

13. Presumably, Yantis and Hillstrom (1994) recognized this problem. In an alternate version of their third experiment, in which they used permanent changes and homogeneous no-change items, the modified item changed to the feature value of the no-change items. That is, one of the display items was originally dimmer than the other items and then increased its luminance to match that of the remaining items. Using this design, which is not entirely unproblematic either, because the change item starts out as a static singleton, Yantis and Hillstrom obtained results that were the same as those with brief transient changes.

14. The appearance of the subjective square is accompanied by offsets in the placeholders, but these offsets are equally present in all conditions and, therefore, cannot account for the observed capture by the subjective square.

15. The velocity of the items was identical in both conditions. Experiments are currently underway to examine the effects of velocity (S. L. Franconeri, personal communication, May, 2001).

16. Because Franconeri and Simons (2001) used two-dimensional displays, the "looming" or "receding" objects were, in reality, expanding or contracting shapes. In both cases, the final size of these shapes at the onset of search did not distinguish them from the other display items.

17. These results conflict with those of Theeuwes (1992), who found no effect of practice on the ability of a singleton to capture attention. Although it is not clear why the results of these studies are at odds with one another, one possibility is that Theeuwes's (1992) results reflected filtering costs and that filtering does not become more efficient with practice. Pending an experimental investigation of the differences between Warner et al.'s (1990) and Theeuwes's (1992) studies, this suggestion has to remain purely speculative, however.

18. Franconeri and Simons's $(2001,2003)$ results with looming objects may constitute an exception: There is no principled argument to suggest that a radial expansion represents an ecologically implausible transformation under any circumstances. It might be argued that certain expansion rates are ecologically implausible and that Franconeri and Simons's $(2001,2003)$ rates were, indeed, too fast to be ecologically plau- sible. However, it is more likely that new-objects-cum-transformation represent a special case of new perceptual objects and that attentioncapturing new objects, in turn, represent a special case of behaviorally urgent events (cf. Franconeri \& Simons, 2003). Looming objects, consequently, capture attention because they are inherently behaviorally urgent without necessarily constituting new perceptual objects. Other strongly modified objects capture attention because they gain behavioral urgency due to their new-object status. All new perceptual objects might, therefore, be behaviorally urgent, but not all behaviorally urgent events involve the appearance of a new object.

19. At this point, invoking the concept of ecological implausibility to account for the results of attentional capture experiments will quickly lead to a circular account, because it is not clear what should be considered ecologically implausible. Ecological implausibility is currently being inferred from the very same capture experiments it is intended to explain. However, principled arguments, such as those offered by Enns et al. (2001), offer a preliminary, reasonable anchoring point with which to tie down the concept of ecological implausibility. Converging evidence affords another source of validation (e.g., Rauschenberger, 2003). Ultimately, it may be desirable, however, to derive empirical data for the parameters that delimit the range of plausible transformations in nature.

20. The only exception is formed by motion cues. However, as was argued in the Motion section, forming the transition between the discussion of feature cues and dynamic cues, a certain class of motion cues can be described as "static" because the motion they display is continuous. Consistent with this classification, "static" motion cues have generally not been found to produce attentional capture (e.g., Hillstrom \& Yantis, 1994), whereas evidence has been mounting that "dynamic" motion cues capture attention (e.g., Franconeri \& Simons, 2003). What the latter share with other dynamic cues is that they are typically indistinguishable from their surrounds once they have ceased moving. "Static" motion cues, by contrast, remain distinctive.

(Manuscript received September 6, 2001; revision accepted for publication January 7, 2003.) 